\title{
LES ABBAYES CISTERCIENNES DE SUISSE
}

\section{† MAUR COCHERIL}

Nous nous proposons d'inaugurer ici une série de monographies consacrées aux abbayes cisterciennes dans les différentes nations européennes où s'est implanté l'Ordre de Cîteaux. Ce genre d'études, telles que nous les concevons, ne concerne pas uniquement l'histoire. Notre propos este surtout pratique: présenter aux érudits un catalogue des monastères en donnant pour chacun d'eux l'essentiel des renseignements d'ordre géographique et chronologique.

Dans une étude publiée ici-même' ${ }^{\prime}$ nous pensons avoir suffisamment démontré que chaque abbaye cistercienne est un cas particulier. Une histoire de l'Ordre de Cîteaux ne peut guère sortir des généralités. Chaque monastère a sa propre histoire, parfois très différente de celle de son proche voisin. On peut, tout au plus, songer à retracer l'histoire des abbayes d'une nation, ou mieux, d'une province. Et là encore, on s'apercevra très vite qu'après quelques pages d'introduction, le reste de l'ouvrage consistera en de brèves monographies ${ }^{2}$. L'histoire n'interviendra dans les études que nous nous proposons de publier que pour montrer l'influence des faits politiques et religieux sur le développement normal de l'Ordre en un pays donné. Elle expliquera pourquoi les abbayes ont pu subsister ici pendant des siècles sans grands dommages, et comment, là, elles ont toutes, ou presque toutes, disparu en l'espace de quelques années. C'est elle encore qui justifiera l'existence d'immenses domaines monastiques dans quelques régions privilégiées ou fera admettre la création des Ordres militaires qui choque notre sensibilité moderne, mais que l'antagonisme de religions militantes explique et justifie.

La présentation des abbayes dans un pays quelconque doit donc débuter par un bref aperçu historique. Il nous a semblé que la Suisse constituait un sujet idéal sous ce rapport. Ce qui s'est passé dans ce petit pays et qu'il est

' P. Maur COCHERIL, L'implantation des abbayes cisterciennes dans la péninsule ibérique, "Anuario de Estudios Medievales», 1, (1964), pp. 216-287.

2 On peut citer en exemple l'excellent travail du R. P. Joseph Canivez, L'Ordre de Cîteaux en Belgique, Scourmont (Belgique), 1926, où l'auteur, après 62 pages de généralités, en consacre 458 à présenter les abbayes une par une. 
possible d'étudier au moyen d'un nombre restreint de monastères s'est reproduit dans toute l'Europe germanique et dans les Pays-Bas. Quand nous aborderons ces régions, il nous suffira de renvoyer le lecteur à la présente étude. Tout se ramène à ceci: les monastères d'hommes s'implantent au XII' siècle. Viennent ensuite les abbayes de moniales à partir du XIII' siècle. Elles sont plus nombreuses que celles de moines, contrairement à d'autres pays comme les Iles Britanniques et la France où ce sont les abbayes d'hommes qui l'emportent. En moins de dix ans, dans la première moitié du XVI' siècle, la Réforme calviniste supprime brutalmente une partie des monastères. Les guerres de la Révolution française et la poussée d'anticléricalisme de 1848 en ferment une autre partie. Quelques maisons de religieuses subsistent pendant que des moines exilés installent à l'étranger des refuges qui deviendront des abbayes florissantes.

L'évolution est donc tout à fait différente de ce qui est advenu dans la péninsule ibérique où l'Ordre n'a connu qu'une seule grande épreuve en 1834 et 1835 , et dans les Iles Britanniques où tout a été balayé au XVI' siècle par le schisme anglican. Nous aurons aussi à étudier la place importante que tient la Suisse dans l'histoire moderne de l'Ordre de Cîteaux du fait qu'elle servit de refue aux Trappistes français pendant la Révolution.

Le plan de notre travail se présente donc tout naturellement de la manière suivante:

A- Histoire de la Suisse.

B- Le milieu géographique

C- Implantation des abbayes

D- Évolution de l'Ordre de 1131 à 1966

E- Les Trappistes en Suisse

F- Table géographique et chronologique des abbayes

\section{Organisation biérarchique des abbayes. Les filiations}

Nous avons longuement exposé dans notre étude sur les abbayes de la péninsule ibérique "les règles impératives auxquelles était soumise toute fondation cistercienne. Nous ne les redonnerons pas ici. Bornons-nous à rappeler simplement le principe des filiations qui est l'une des caractéristiques de la législation de l'Ordre. Ce principe est le suivant. Toute abbaye cistercienne, conformément à la Règle de saint Benoît, jouit d'une large autonomie. Le Patriarche des moines n'a pas légiféré pour un Ordre, mais pour un monastère. Ce n'est que beaucoup plus tard, avec Cluny et Cîteaux, que l'on a groupé des abbayes en un seul corps, sous l'autorité d'un supérieur muni de pouvoirs plus ou moins étendus. A l'origine le monastère bénédictin est une entité. Les moines ne dépendent que de l'abbé. Cette autonomie absolue peut être

'Cf., ci-dessus, note 1. 
préjudiciable comme l'a démontré l'histoire monastique. Pour obvier à cet inconvénient tout en préservant les droits de l'abbé et de son convent, les législateurs cisterciens imaginèrent de créer entre toutes les abbayes un lien d'interdépendance qui garantirait l'unité de discipline et d'observance dans toutes les maisons, qui serait suffisament fort pour empêcher les déviations de tous genres, mais qui, en même temps, serait assez souple pour ne pas entraver la légitime liberté de l'abbé et des moines de chaque monastère.

On décida d'unir chaque abbaye à celle qui l'avait fondée. Celle-ci était l'abbaye-mère, et celle-là, l'abbaye-fille. L'autonomie financière et administrative de la maison-fille était préservée. En matière de discipline monastique et d'observance, l'abbeye-mère conservait un droit de surveillance. Son abbé visitait sa fille chaque année. Cette Visite régulière, ainsi qu'elle est appelée, lui permettait de se rendre compte de la manière dont la Règle était observée et de redresser les déviations en usant de son droit de surveillance. Il était aussi tenu de vérifier la situation matérielle et financière de la maison. Au cours de la Visite, il entendait chacun des religieux qui devait lui donner librement son avis. Ce dernier point est très important car il constituait un frein au despotisme de certains abbés qui pouvaient être tentés d'abuser de leur autorité. Ce double contrôle exercé sur le chef du monastère par l'abbé-père et par les moines fut bénéfique à tous égards. Quand le système des Visites régulières tomba en désuétude à certaines époques, il s'ensuivit une réelle décadence.

L'abbaye-fille qui fonsait une autre maison devenait à son tour la mère de celle-ci et se comportait à son égard exactement comme le faisait sa fondatrice à son endroit. Mais à mesure que se multipliaient les générations d'abbayes, le lien de filiation s'amenuisait. Si nous prenons comme exemple une abbaye que nous appellerons " $A$ », lorsqu'elle en a fondé une autre que nous désignerons par « $B$ », il y aura entre elles des relations étroites de mère à fille. Quand «B», à son tour, aura fondé " $C »$, " $A$ » n'aura aucun droit sur cette dernière. Ce sera «B» qui la visitera. Et «C», à son tour, peut aussi fonder «D». De même manière «B» $n$ 'interviendra pas dans les affaires de «D». Cependant nous dirons que «B», "C » et «D» sont dans la filiation de "A», et pour employer le langage cistercien, nous établirons la généalogie de la maniere suivante: " $A$ » est la mère, «B» est la fille, " $C$ », la petite-fille et «D», l'arrière-petite-fille. Les abbayes sont ainsi organisées selon une hiérarchie échelonnée. Chacune d'elles dépendait toujours d'une abbaye-mère, mais d'une seule. Cette solution coupait court à toute centralisation excessive. Il restait encore à organiser cette hiérarchie au sommet. On décida donc que l'abbaye de Cîteaux, Mère et Maîtresse de toutes les Églises de l'Ordre, et de qui, à y bien regarder, étaient sorties absolument toutes les autres abbayes, ne serait pas l'unique chef de filiation comme il aurait été logique. On lui adjoignit les quatre premiers monastères qu'elle avait fondés de manière à constituer avec elle cinq grandes filiations dans lesquelles viendraient se ranger toutes les autres maisons. 
Cîteaux conservait une prééminence honorifique. Elle ne pouvait échapper à la Visite régulière, elle non plus, en tant que maison religieuse. Par respect pour l'Archiabbaye et pour le "Seigneur Abbé de Cîteaux», on établit que le monastère serait visité conjointement par les quatre Premiers Pères. De cette manière aucun abbé et aucun monastère n'était soustrait à la loi générale.

On voit par le tableau des filiations des abbayes suisses que nous donnons ici comment Wettingen, la plus récente fondation, est reliée à Cîteaux par une série d'abbayes intermédiaires: Salem, Lucelle, Bellevaux et Morimond. Wettingen, fille de Salem, appartient à la lignée de Morimond, monastère chef de filiation. Kappel, au contraire, fille d'Hauterive, se place dans celle de Clairvaux. Cîteaux n'ayant fondé aucune abbaye en Suisse n'en a pas dans sa propre filiation et nous ne trouverons dans ce pays que les deux lignées de Clairvaux et de Morimond.

Le caractère international de l'Ordre est bien mis en évidence ici. Nous avons deux abbayes françaises dans la généalogie de Wettingen, Morimond et Bellevaux, et une abbaye allemande, Salem. Le cas de Lucelle est un peu particulier du fait de sa localisation qui en fait une abbaye germanique sise aujourd'hui en territoire français.

Le système des filiations ne s'appliquait pas aux monastères de femmes. Beaucoup d'entre eux étaient des affiliations, c'est-à-dire qu'il s'agissait de couvents féminins appartenant à un autre Ordre qui demandaient à entrer dans celui de Cîteaux. Presque tous ceux de Suisse sont dans ce cas. Chaque monastère de moniales était rattaché à une abbaye de moines dont l'abbé devenait Père-Immédiat de la maison féminine. D'après Winter ${ }^{4}$ l'abbaye de Bellevaux dépendait de Cîteaux, et celle de Bellerive, de Clairvaux. Ordinairement le Père-Immédiat était l'abbé du monastère masculin le plus proche.

\section{A. HISTOIRE DE LA SUISSE}

\section{Formation des premiers Cantons}

La Suisse, ou pour être plus précis, la Confédération Helvétique, n'existait pas quand les cisterciens s'installèrent sur son territoire actuel. Cette région montagneuse comportait en son centre des vallées où végétait une population misérable, menant une vie très dure et tirant ses ressources de l'élevage des troupeaux. Le lac de Lucerne (Lac des Quatre Cantons) unissait entre elles les vallées. Celles-ci dépendaient, en principe, des seigneurs de Habsbourg, forteresse établie à petite distance de la rive droite de l'Aar, dans le Canton

4 Franz WINTER, Die Cistercienser des nordöstlichen Deutschlands, III, Gotha, 1871, pp. 180 et 183. 
d'Argovie '. Le reste du territoire ressortissait aux évéchés de Genève, Sion, Bâle et Saint-Gall englobés dans les duchés de Milan et de Souabe et dans le comté de Savoie. Une partie du Valais actuel et des Grisons ne comprenait que des unions de villages. Certaines villes le long du Rhin ou sur le plateau obtinrent très tôt le privilège de s'administrer elles-mêmes. L'empereur, désireux d'obtenir leur appui, les affranchit de la tutelle des seigneurs. Devenues villes impériales, elles pouvaient conclure des traités et acheter des terres. Berne, Zurich et Soleure (Solothurn), noyaux de trois futurs Cantons, étaient villes impériales. Quelques seigneurs cherchaient à se constituer en Etats indépendants. Les Habsbourg, originaires d'Alsace, rayonnaient depuis l'Argovie dans différentes directions. Les Savoie s'étaient installés sur les rives du Léman et dans la vallée du Rhône.

Telle était la situation quand les cisterciens s'installèrent dans cette région. Il faut noter que le pays de l'ouest, par Genève et Lausanne, était en relations étroites avec la Bourgogne, ce qui explique la pénétration de la filiation de Clairvaux dans cette région.

Au point de vue linguistique le partage se fit très tôt. Les Alamans descendirent du nord-ouest, occupèrent le plateau entre le lac de Constance et le lac de Lucerne et s'enfoncèrent dans les vallées des Alpes. Les Ostrogoths venus d'Italie s'établirent dans le Tessin supérieur et jusqu'aux rives du lac de Lucerne et du Walensee. Une deuxième poussée germanique aux $\mathrm{XI}^{\mathrm{c}}$ et $\mathrm{XII}^{\mathrm{c}}$ siècles fit progresser légèrement à l'ouest le domaine de l'allemand jusqu'à une ligne qui correspond à peu près à la frontière linguistique moderne. Les Burgones installés à l'ouest furent assimilés par les populations gallo-romaines et abandonnèrent la langue germanique ${ }^{6}$.

Pendant l'occupation franque (VI'-IX' siècle), les sièges épiscopaux furent définitivament installés à Bâle, Constance et Sion. La colonisation monastique se développa à Saint-Gall, Dissentis, Einsieldeln et Engelberg. Au démenbrement de l'Empire de Charlemagne en 887, le territoire fut partagé entre le royaume germanique et celui des Burgondes. La ligne de partage partait du col du Saint-Gothard, passait par Lucerne et joignait le Rhin au confluent de l'Aar' . La partie située à l'ouest de cette ligne forma la province de Bourgogne cisjurane.

' Nous donnons dans le texte les noms français des Cantons. Nous nous sommes conformés à l'usage en indiquant sur les cartes les noms dans la langue originale. Voir dans la table des monastères les transcriptions en allemand et en français.

6 Cf. pour tout ceci, Gordon EAST, Géographie historique de l'Europe, Paris, Gallimard, éd. 1939, pp. 220 et suiv., et surtout Albert DAUZAT, L'Europe linguistique, Paris, Payot, 1953, pp. 158 et suiv.; carte, pp. 167-168.

Barata, Fraccaro et Visintin, Atlante Storico, Novara, 1961, fasc. II, Medio Evo, carte 9, L'Imperio al Tempo degli Hohenstaufen. 
L'ouverture de la route commerciale qui, par Bâle, Lucerne et le SaintGothard, reliait Bruges à Venise, tira de leur condition misérable les paysans du pays d'Uri et ceux de Schwyz. Depuis des temps reculés, ils étaient groupés en communautés rurales. Ils se rasssemblaient à intervalles réguliers pour tenir des assemblées (landsgemeinde) où chacun donnait librement son avis. Ils en vinrent ainsi à s'intéresser à la situation politique surtout afin de défendre leurs droits. Avec les bénéfices du portage des marchandises qui transitaient par leurs vallées, ils purent racheter aux Habsbourg les droits seigneuriaux, puis ils obtinrent de l'Empereur le droit d'immédiateté analogue à celui dont jouissaient déjà les villes. Ceure d'Uri l'obtinrent en 1231, et ceux de Schwyz en 1240. Ils étaient pratiquement autonomes pendant le Grand interrègne (1250-1273) qui suivit la mort de Frédéric II de Hohenstaufen. Cette autonomie fut menacée quand Rodolphe de Habsbourg fut élu Empereur. Sa famille n'avait jamais reconnu le droit d'ancienneté des Schwyzois. Les communautés sentirent le besoin de s'unir étroitement pour défendre leurs libertés.

Les gens de l'Unterwald composaient deux communautés: Obwald et Nidwald. Les trois pays, Uri, Schwyz et Unterwald formaient les Waldstaetten, nom tiré des vastes forêts qui couvraient la région. Les Unterwaldiens étaient tenus en servage par les Habsbourg. À la mort de Rodolphe (15 juillet 1291), les Waldstaetten s'unirent par un pacte d'alliance défensive. "Considérant la malice des temps et pour être mieux à même de défendre et maintenir dans leur intégrité leurs vies et leurs biens, les gens de la vallée d'Uri, la landsgemeinde de la vallée de Schwytz et celle des gens de la vallée inférieure d'Unterwald» ${ }^{8}$ s'engagèrent au début du mois d'août de 1291 à s'aider les uns les autres en cas d'attaque. Ce pacte «juré» des Waldstaetten constitue l'acte de fondation de la Confédération Suisse. À cette époque remontent les légendes des héros luttant contre les baillis envoyés par les Habsbourg. Le plus célèbre est Guillaume Tell, adversaire de Gessler, bailli de Schwyz et d'Uri.

Léopold d'Autriche fut battu par les Confédérés à Morgaten en 1315. Les Waldsteatten renforcèrent leur alliance par le pacte de Brunnen, et comme les gens de Schwyz s'étaient particulièrement distingués dans cette guerre, leur nom servit peu à peu à désigner les Confédérés devenus les Suisses. Lucerne se rallia à la Confédération en 1332, Zurich en 1351, Zug et Glaris en 1352, Berne en 1353. La nouvelle Confédération dite des buit Cantons était assez disparate puisqu'à côté des Cantons purement démocratiques, les Waldstaetten et Glaris, elle en comprenait quatre, Lucerne, Berne, Zug et Zurich où une partie de la population était soumise à la bourgeoisie qui administrait les villes. Cette Confédération ne se fit pas sans difficultés. Pour mettre fin à l'influence

8 Traduction du pacte de 1291 dans GIDDEY, Histoire Générale du XIV' au XVIII' siècle, Payot, Lausanne, 1964. 
des Habsbourg à Zug, ville qui se trouvait entre Zurich et ses alliés, les Confédérés l'obligèrent à s'unir à eux après l'avoir réduite par un siège. Les gens de Schwyz en profitèrent pour saccager l'abbaye de religieuses cisterciennes de Frauenthal. Ce monastère fut de nouveau pillé par les Autrichiens en 1388, lors de la deuxième campagne contre les Habsbourg.

Le nombre des Cantons ne changea pas pendant la première moitié du $\mathrm{XV}^{\mathrm{c}}$ siècle. La Confédération se fortifia en signant des traités d'alliance avec les États voisins, soit des villes comme Soleure, Neuchâtel, Saint-Gall, Bâle, Schaffhouse et Mulhouse, soit avec des seigneuries ecclésiastiques à Sion et à Saint-Gall, soit avec les communautés paysannes d'Appenzell et des Grisons. Elle annexa aussi les vallée tessionoises, l'Argovie et la Thurgovie qui furent administrées par des baillis. Les luttes d'influence entre certains Cantons provoquèrent des guerres courtes, mais désastreuses pour les établissements monastiques trop souvent saccagés et pillés malgré le Convenant de Sempach qui punissait les soldats qui profanaient les églises ou qui pillaient «sans en avoir reçu l'ordre». Kappel fut saccagé par les Confédérés en 1413. Fraubrunnen fut incendié en 1260 et en 1375 .

Au début du XVI' siècle, après l'entrée de Bâle et de Neuchâtel dans le Confédération en 1501, et d'Appenzell en 1513, la Suisse comprenait treize Cantons. Sa situation politique était consolidée. A la suite de la guerre dite de Souabe qui se termina par la victoire des Suisses à Dornach, près de Bâle, (1499), l'Empereur signa la paix et reconnut tacitement une indépendance qui ne devint officielle qu'en 1648, au Traité de Westphalie. Le prestige militaire des Suisses était à son apogée quand la Réforme mit en péril l'unité de la Confédération.

\section{Zwingle et la Réforme}

On admet que les causes de la Réforme en Suisse allemande furent les mêmes qu'en Allemagne, avec cependant ce correctif que le clergé était, dans son ensemble, moins corrompu et plus proche du peuple. Mais, surtout dans les villes, l'influence des humanistes fut prépondérante. Les cantons paysans demeurèrent catholiques. Les Waldstaetten furent le bastion de la résistance aux idées nouvelles. Le principal artisan de la Réforme en Suisse allemande fut Ulrich Zwingle, par ailleurs adversaire de Luther. Il commença à prêcher en 1516 contre le culte de la Vierge. Passé à Zurich, il devint prédicateur de la cathédrale. Les autorités de la ville l'autorisèrent à soutenir ses thèses en 1519 dans une discussion publique. Au cours de cette Dispute de Zurich les catholiques eurent le dessous. Le protestantisme devint la religion officielle de Zurich en 1525 . Zwingle fut autorisé à fermer les couvents. L'abbaye de cisterciennes de Selnau, sous les murs de ville, fut sécularisée en 1525 , et celle de moines de Kappel en 1527. 
Le réformateur fit triompher ses idées à Berne et à Schaffhouse, Cantons qui devinrent protestants. A Bâle, le moine apostat OEcolampe obtint en 1527 des catholiques la liberté pour le nouveau culte. Tout alla très vite. Il épousa en 1528 une veuve qui, après sa mort, épousa deux autres réformateurs, Capito et Brucer. En 1529 il fit interdire le culte catholique par le Conseil de la ville. À Glaris et à Appenzell, les réformés ne parvinrent pas à éliminer le catholicisme. À Saint-Gall la ville devint protestante, mais l'abbé maintint l'ancienne religion dans les campagnes. Comme conséquence logique du passage des Cantons au protestantisme les monastères furent sécularisés. Frienisberg, Fraubrunnen et Tetligen, dans celui de Berne, furent fermés en 1528. Engenthal, dans la campagne de Bâle, détruit en 1525 , fut définitivement supprimé en 1534. Kalchrain, dans le Canton de Thurgovie, fut fermé en 1529 en même temps que Magdenau dans le Canton de Saint-Gall. Frauenthal, à Zurg, avait été sécularisé en 1528. Tanikon (Thurgovie) fut abandonné en 1529 par les religieuses qui passèrent à la Réforme.

Les Cantons centraux, Uri, Schwyz, Unterwald, Lucerne, Zug, ainsi que les villes de Fribourg et de Soleure, refusèrent la Réforme. Avec l'Autriche, le Valais et la Savoie, elles formèrent une Alliance cbrétienne. Les protestants: Zurich, Berne, Schaffhouse, Bâle, les villes alliées de Saint-Gall, Constance et Strasbourg, signèrent un Traité de combourgeoisie chrétienne. Une guerre civile et religieuse était inévitable. Elle se doublait de l'antagonisme entre les Cantons paysans et les villes. Sous l'influence de Zwingle, Zurich déclara la guerre aux catholiques en 1529. Les armées se rencontrèrent près de Kappel, mais il n'y eut pas de combat. Les chefs s'assemblèrent pour trouver une solution à l'amiable. Comme les protestants étaient les plus nombreux, ils imposèrent leurs vues. L'Alliance chrétienne fut dissoute. On laissa les baillages communs libres de choisir leur religion. Ce n'était pourtant pas de la tolérance. En vertu de l'adage alors communément admis: cujus regio, ejus religio. expression latine que l'on peut traduirte librement: «la religion du souverain doit être celle de ses sujets», on n'autorisait dans les baillages de la religion de la majorité. La minorité devait s'incliner.

Zwingle ne désarmait pas. Les catholiques excédés reprirent les armes en 1531 et attaquèrent les Zurichois. La rencontre eut encore lieu à Kappel, non loin de l'abbaye cistercienne supprimée en 1527. Zwingle fut tué dans le combat par le capitaine Unterwaldien Vokinger. Zurich dut renoncer à la combourgeoisie et les minorités castholiques des baillages communs obtinrent la liberté du culte.

Le développement de la Réforme en Suisse allemande avait été stoppé après la bataille de Kappel. Elle s'étendit alors à la Suisse romande. Cette région était politiquement très morcelée. On y trouvait des seigneurs laïcs et ecclésiastiques ainsi que des villes indépendants ou soumis à des suzerains. Le 
duc de Savoie possédait la majeure partie du pays de Vaud. Quelques villes avaient obtenu le droit de s'administrer elles-mêmes. Dans Genève, ville d'Empire qui formait un véritable petit État avec les terres lui appartenant, et dont il voulait faire sa capitale, le duc s'efforçait d'étendre son influence au détriment des bourgeois dont la situation était encore plus désagréable quand l'évêque était un membre de la famille de Savoie. Cette influence du duc se faisait aussi vivement sentir à Lausanne, autre ville d'Empire jouissant d'un statut analogue à celui de Genève.

Berne qui ne pouvait s'agrandir à l'est cherchait à s'étendre à l'ouest. Elle possédait en Suisse romande quelques villes et administrait avec Fribourg les baillages communs de Grandson, Orbe, Echallens et Morat. Elle était encore l'alliée du petit comté de Neuchâtel et englobait dans sa zone d'influence l'actuel Jura bernois soumis, en principe, à l'évêque de Bâle. Les Bernois s'étaient faits les champions du protestantisme auquel ils avaient adhéré en 1528. Ils appuyèrent l'action du prédicant Guillaume Farel qui convertit les baillages communs de Morat et de Grandson. C'est à Orbe que Farel gagna à la Réforme Pierre Viret. Farel convertit ensuite Neuchâtel (1530). Il éprouva d'abord quelques déboires à Genève d'où il fut chassé. Mais soutenu par Berne il put enfin prêcher sans entraves. Le culte catholique fut suspendu dans la ville en 1535. Fribourg, qui demeurait attachée à la foi romaine, rompit alors son alliance avec les Bernois.

Les bourgeois de Genève hostiles à la Savoie avaient pris le surnom d'Enfants de Genève. On leur appliquait aussi le sobriquet d'Eidguenots, dont nous avons fait Huguenots, parce qu'ils soutenaient les Confédérés ou Eidgenossen. La ville était divisée en factions armées qui multipliaient les rixes et les attentats. La situation empira quand le duc de Savoie marcha contre Genève au début de 1536. Les Eidguenots, alors maîtres de la situation, ne pouvaient demander de l'aide aux Fribourgeois catholiques. Ils se tournèrent vers les Bernois qui mobilisèrent 6.000 hommes et entrèrent dans le Pays de Vaud. L'expédition ne rencontra aucune résistance. Les Fribourgeois et les Valaisans s'armèrent à leur tour contre le duc de Savoie, cependant catholique comme eux. Fribourg s'empara de Romont, Châtel-Saint-Denis, Bulle et Estavayer. Les Valisans soumirent une partie du Bas-Valais actuel et le Chablais.

Farel et Viret gagnèrent à la Réforme les baillages organisés par Berne sur ses conquêtes. Ceux des territoires occupés par Fribourg et les Valaisans demeurèrent catholiques. En cette même année 1536, les deux prédicants avaient retenu Calvin de passage à Genève. A la fin de l'année, conformément à une coutume qui tendait à s'imposer partout où les deux confessions s'affrontaient, on organisa une réunion contradictoire dans la cathédrale de Lausanne. Toujours soutenus par les Bernois, les protestants eurent le dessus dans cette Dispute de Lausanne. Le protestantisme devint seule religion tolérée. 
À la suite de ces événements, les abbayes cisterciennes de Bellerive, Bellevaux, Bonmont, Hautcrêt et Monthreron furent sécularisées en 1536. Mais celle de la Fille-Dieu, aux portes de la ville de Romont, dans le territoire conquis par Fribourg, ne fut pas inquiétée.

La Réforme avait divisé la Suisse en deux clans hostiles et les rivalités confessionnelles venant s'ajouter aux luttes politiques entre Cantons menaçaient dangereusement la cohésion de la Confédération. Ce fut la diplomatie française qui la sauva en gagnant à sa cause l'ensemble des Suisses. Henri IV signa avec eux une alliance en 1602. Les Cantons s'organisèrent pour vivre en bonne harmoine malgré les devergences religieuses qui les séparaient désormais. Le Canton d'Appenzell où les catholiques et les protestants étaient à égalité fut divisé en deux demi-cantons en 1597. L'abbé de Saint-Gall ramena au catholicisme une partie de ses domaines et l'abbaye de Magdenau qui avait été fermée en 1529 fut restaurée en 1532. Ce monastère repeupla Tänikon (Thurgovie) en 1550. Frauenthal, dans le Canton de Zug, fut restauré en 1552, et celui de Kalchrain, en Thurgovie, le fut en 1562.

Les troubles religieux reprirent au XVIII' siècle. Les catholiques furent vainqueurs de la première guerre de Vilmergen (1656) au cours de laquelle le monastère de Mariazell-Wurmsbach eut à souffrir. La guerre du Toggenburg, en 1712, se termina par la victoire des protestants. La paix d'Aarau établit enfin l'égalité des religions et apaisa les esprits. L'abbaye d'Eschenbach (Lucerne) dut être abandonnée deux fois au cours de ces guerres civiles.

Le monastère de Lucelle qui se trouvait en territoire français fut sécularisé à la suite du décret du 13 février 1790 de l'Assemblée Constituante qui supprimait les Ordres religieux. Sa disparition entraînait celle du prieuré de Kleinlützel situé dans une enclave du Canton de Soleure dans celui de Berne, et que les moines de Lucelle avaient choisi en 1505 pour leur servir de refuge. L'abbaye d'Olsberge n'avait jamais appartenu à la Suisse. À la suite de l'Acte de Médiation imposé en 1803 par Napoléon, la frontière fut délimitée par la rive gauche du Rhin et ce monastère entra dans le Canton d'Argovie. Il fut sécularisé le 29 mai 1805 . Les autres monastères souffrirent des déprédations des troupes en campagne, mais, à l'exception de la Trappe de la Valsainte dont nous parlerons plus loin, ils ne furent pas dissous.

\section{Le mouvement radical}

La Suisse ne pouvait se tenir à l'écart des mouvements d'idées qui agitèrent l'Europe après la chute de l'Empire. Malgré les gouvernements conservateurs où, comme à Berne, Lucerne, Fribourg et Soleure, on avait rendu leurs privilèges aux familles patriciennes, tandis qu'à Zurich, à Bâle et à Schaffhouse les corporations de la ville s'imposaient aux populations paysan- 
nes, la Confédération fut souvent à l'avant-garde. Les grandes puissances la tenaient en tutelle. L'autonomie des Cantons était renforcée «jusqu'au cantonalisme les plus étriqué» '. Si les libertés civiques étaient restreintes et certaines, comme la liberté de la presse, complètement supprimées dans certains Cantons, il en alla de même de la liberté religieuse. Le culte officiel, protestant ou catholique, était le seul autorisé. Un protestant n'avait pas le droit de s'établir dans l'un de ces bastions du catholicisme qu'étaient les Cantons primitifs. Cette situation empira à partir de 1820 quand se déclancha le mouvement religieux appelé "Réveil». Il tendait à ranimer, à «réveiller» la vocation chrétienne. Analogue au «revival» qui se manifeste de temps à autres aux États-Unis, il provoquait par les extravagances de trop de nouveaux convertis l'hostilité des Églises établies et la rigueur policière des autorités cantonales peu soucieuses de mysticisme. Le fanatisme y trouvait aussi son compte.

La réaction contre ces entraves ne se fit pas attendre. La chute de Charles $\mathrm{X}$, en France, déclancha, sous la pression des idées libérales, des révolutions dans les principaux Cantons. Dans ceux de Berne, Saint-Gall et Fribourg, les gouvernements conservateurs cédèrent la place aux libéraux. Quand ceux-ci voulurent réformer le Pacte de 1815 pour donner plus d'unité et de force à la Confédération, ils se heurtèrent à l'hostilité des conservateurs encore influents dans les Cantons catholiques qui craignaient de voir les protestants devenir prépondérants dans une Suisse unifiée.

L'aile gauche du libéralisme s'orienta alors vers un radicalisme intransigeant. Plus énergiques et moins scrupuleux que les libéraux, plus près du peuple aussi et plus réalistes, les chefs radicaux entendaient renforcer le lien fédéral en l'imposant à la minorité, au besoin par la force. Leur programme de réforme sociales n'a rien qui puisse nous étonner aujourd'hui. Il faut souligner par contre l'anticléricalisme de certains chefs radicaux, surtout dans les Cantons catholiques. Ils reprochaient au clergé ses compromissions avec la bourgeoisie conservatrice, sa tiédeur, pour ne pas écrire son hostilité, à l'égard des idées démocratiques. Sous ce rapport la situation se dégrada très vite.

L'affaire des couvents d'Argovie (1841-1843) fut l'occasion de premières escarmouches. Dans ce Canton mixte à majorité protestante, la Constitution avait réservé un nombre égal de sièges au Grand Conseil aux deux confessions. Les autorités cantonales prétendirent, en 1841, répartir ces sièges proportionnellement à la population, ce qui donnait la majorité aux protestants. Les catholiques se soulevèrent. La révolte fut réprimée, mais le Conseil en rendit responsables les couvents et les supprima. Cette décision violait le Pacte de 1815 dans la mesure où celui-ci garantissait la liberté du culte dans les Cantons 1964.

9 G.A. Chevallaz, Histoire Générale de 1789 à nous jours, Payot, Lausanne, 
mixtes. La Diète fédérale saisie de l'affaire cassa l'arrêt du Grand Conseil, mais, en raison de l'opposition des radicaux, elle ne put faire rétablir que les couvents de femmes. A la suite de cette malencontreuse affaire, l'abbaye de moines de Wettingen fut sécularisée le 13 janvier 1841. Celle de moniales de Gnadenthal avait été supprimée en même temps. Conformément à la decisión de la Diète fédérale, elle fut rétablie le 31 août 1843 avec le titre de prieuré.

Un peu plus tard, le Grand Conseil du Canton catholique de Lucerne décida de confier aux jésuites l'enseignement secondaire. Il en avait strictement le droit, mais dans l'état de tension où se trouvait alors la Confédération, cette initiative prenait l'allure d'une provocation. Les radicaux demandèrent à la Diète de faire revenir Lucerne sur sa décision. Ils n'avaient pas la majorité et ils n'obtinrent pas satisfaction. Ils recoururent à l'intimidation. Deux expéditions de "corps francs» envahirent le territoire de Lucerne et furent repoussés. N'accordant pas foi aux protestations de la Diète qui condamnait ces expéditions, les sept Cantons catholiques de Lucerne, Schwyz, Unterwald, Zug, Uri, Fribourg et Valais, en prirent prétexte en 1845 pour conclure une alliance "séparée» (Sonderbund) afin de défendre leur souveraineté cantonale. Cette ligue eut le tort de solliciter l'appui des gouvernements français, autrichien et sarde préoccupés par l'influence croissante du radicalisme en Suisse. La Confédération était menacée à la fois d'une guerre civile et de l'invasion étrangère. Sur ces entrefaites, les élections de 1847 amenèrent à la Diète une majorité radicale. Le Sonderbund fut immédiatement déclaré illégal et sommé de se dissoudre. Les sept Cantons refusèrent. L'armée fédérale conduite par le général Dufour eut facilement raison des dissidents à la suite d'une campagne, d'ailleurs peu sanglante, qui ne dura pas un mois. Le Sonderbund fut dissous et les jésuites chassés de Suissé. Les troupes étrangères qui n'avaient plus aucune raison d'intervenir furent rappelées.

Il est évident que la déconfiture du Sonderbund devait avoir des conséquences désastreuses pour les établissements religieux. Dans le Canton de Lucerne, les abbayes de Sant Urban (moines) et de Rathausen (moniales) furent supprimées par un décret du 13 avril 1848. Les cisterciennes d'Eschenbach, dans le même Canton, furent épargnées, mais, jusqu'en 1872, il leur fut interdit de recevoir des novices, ce qui les condamnait à périr par manque de vocations. Dans le Canton de Thurgovie, les trois abbayes féminines de Feldbach, Kalchrain et Tänikon furent sécularisées le 27 juin 1848. L'abbaye d'hommes d'Hauterive, dans le Canton de Fribourg, fut fermée par un décret du 28 mars 1848. Les cisterciennes de la Fille-Dieu et de la Maigrauge, dans le même Canton, étaient condamnées à disparaître "par voie d'extinction». On remarquera que les monastères furent supprimés même dans deux Cantons catholiques, Lucerne et Fribourg. 
À la suite de cette hécatombe, il ne restait plus un seul monastère masculin cistercien en Suisse. Nous ne voyons que les abbayes féminines de Gnadenthal (Argovie), Frauenthal (Zug), Mariazell-Wurmsbach et Magdenau (SaintGall) qui ne furent pas inquiétées. Les monastères condamenés à disparaître «par voie d'extincion» furent autorisés en 1872 à recevoir des novices, ce qui les sauva. Celui de Gnadenthal (Argovie) que avait été restauré comme prieuré en 1843 disparut en $1876^{\prime \prime}$.

De nouveaux conflits entre les Cantons, un réveil de l'anticléricalisme apparenté au Kulturkampf allemand à la suite de la proclamation du dogme de l'infaillibilité pontificale par le Premier concile du Vatican (1870), d'autres raisons d'ordre politique ou simplement administratif, aboutirent à l'élaboration d'une nouvelle Constitution fédérale en 1874. Elle interdisait, entre autres choses, de créer de nouveaux couvents. Cette disposition était grave de conséquences puisqu'elle rendait impossible la restauration des antiques monastères de l'Ordre.

Les querelles du passé s'estompèrent peu à peu. Dans le Canton de Fribourg une Université catholique internationale "fut fondée en 1889. Berne, capitale fédérale, accepta en 1920 un Nonce apostolique. Après d'assez longs pourparlers, l'École Normale d'instituteurs installés dans l'abbaye d'Hauterive en 1858 fut transférée à Fribourg et, le 3 août 1939, les cisterciens revenainent dans la vieille abbaye que le Conseil, respectueux de la Constitucion, leur louait à bail.

\section{B. LE MILIEU GÉOGRAPHIQUE}

Le milieu géographique où pouvaient s'implanter en Suisse les abbayes cisterciennes est nettement déterminé: le plateau orienté sud-ouest/nord-est, joignant le lac de Genève au lac de Constance. Bordé au nord par la chaîne du Jura et au sud par les Alpes, il s'ouvre largement au nord jusqu'au Rhin. Les Alpes sont entaillées par de larges vallées, voies de pénétration naturelles qui ont été le berceau de la Confédération. Le reste du territoire comprend le secteur central des Alpes depuis le Mont-Blanc jusqu'à l'Ortler, absolument impropre à la culture. Ce que nous savons des exigences des cisterciens et de leur politique agricole ${ }^{12}$ nous permet de borner cette brève note géographique au planteau et aux vallées, seul habitat possible et logique pour nos moines. nologie.

10 Voir à la table des monastères, notice "Gnadenthal», la justification de cette chro-

"En même temps Université d'État du Canton.

12 Cf. la première partie de notre étude sur l'Implantation des abbayes cisterciennes dans la péninsule ibérique. 
Notons tout-de-suite qu'au contraire de ce qui s'est produit en Espagne et au Portugal, les abbayes féminines sont en majeure partie rurales, même celles qui sont aux portes des villes. Pour cette raison nous les étudierons ici avec les monastères masculins. Nous prendrons pour guide l'étude d'Henri Onde dans le premier volume de la Géographie Universelle Larousse en y joignant les cartes du Service topographique fédéral suisse et les autres documents cartographiques rassemblés pour ce travail.

La structure morphologique de la Confédération se présente selon quatre axes parallèles orientés sud-ouest/nord-est suivant un angle moyen de $35^{\circ}$. Ce sont, du nord au sud, la chaine du Jura; le plateau ou Moyen Pays; les Alpes divisées en massifs: Alpes bernoises (Berner Alpen) entre le Rhône et l'Aar supérieur, l'Unterwalden (Unterwaldener Alpen) entre l'Aar et le lac des Quatre Cantons prolongé par la Reuss supérieure, les Alpes grises (Glaner Alpen); le cours supérieur du Rhône et celui du Rhin (Vorder Rhein). Mais l'histoire et la división linguistique contredisent cette morphologie. Il en va de même des divisions confessionnelles et politiques. Le phénomène est le même qu'en Afrique du nord et particulièrement en Algérie orientée de la même manière, mais oì l'on distingue transversalement une Oranie, un Algérois et un Constantinois. L'ambigüité de la partition traditionnelle, Alpes, Plateau et Jura, amène à préférer la suivante: Suisse occidentale, Suisse médiane et Suisse orientale.

\section{Suisse occidentale}

Cette région comprend les Cantons de Genève, de Vaud, de Fribourg, du Valais, de Neuchâtel, de Berne et la partie méridionale de celui de Soleure. Elle englobe absolument toute la Suisse d'expression française et la frange occidentale de la Suisse allémanique. Elle se présente à nous comme un vaste carrefour. La route joignant la Franche-Comté à l'Italie longe les rives du Léman et atteint le Grand-Saint-Bernard en suivant le Rhône. Cette voie aura une grande importance dans le peuplement cistercien de la Romandie car saint Bernard l'empruntera au cours de ses voyages. Une autre route partant de Lausanne se dirige vers Pontarlier et la Bourgogne. C'est à travers cette región que serpente la route de Milan à la Champagne et à la Flandre, route des marchands et des pèlerins.

L'itinéraire du quatrième voyage de l'abbé de Clairvaux demeure inconnu. Bernard Bligny avance l'hypothèse qu'il traversait l'Helvétie. ${ }^{13} \mathrm{C}$ 'était en 1137, à l'époque des affiliations de prieurés et d'abbayes bénédictines. Le

13 Bernard BLIGNY, L'Église et les ordres religieux dans le royaume de Bourgogne aux XI' et XIr siècles, Paris, P.U.F., 1960, p. 349. 
biographe de saint Bernard rapporte que c'est en allant de Lausanne à Genève qu'il demeura plongé dans une contemplation si profonde qu'il fut tout étonné d'apprendre le soir qu'il avait cotoyé pendant de longues heures un lac magnifique sans s'en apercevoir ${ }^{14}$.

Cette Suisse occidentale tendit très vite, au moyen âge, à devenir une entité politique et religieuse quand les limites du diocèse de Lausanne furent fixées sur l'Aar, tandis que la Savoie étendait son influence depuis Sion jusqu'à Morat, au nord du Canton de Fribourg. L'État de Berne ayant supplanté la Savoie dans la première moitié du XVI' siècle occupa peu à peu toute la région en englobant le Pays de Vaud qu'il conserva jusqu'en 1798. Les communications étaient continuelles avec la Bourgogne, la Franche-Comté et la Savoie, favorisées par la comunauté de langue. Les alliances entre les grandes families seigneuriales des deux versants du Jura contribuaient à renforcer ces liens et elles auront leur importance dans la fondations des monastères de la contrée.

Celle-ci est comprise toute entière dans la zone proprement agricole. Bien exposée, moyennement arrosée, elle se prête à la culture de la vigne. On y trouve 70 por 100 du vignoble suisse. Le vignoble vaudois est le plus important. En bordure du Jorat, les moines de Montheron et de Hautcrêt défrichèrent le Dézaley, côteau qui domine le Léman entre Saint-Saphorin et Villette. Ils y plantèrent de la vigne importée de Bourgogne à laquelle le terroir confere un bouquet capiteux. Le Dézaley est toujours le premier crû vaudois. Exploités aujourd'hui par la ville de Lausanne qui en est devenue propriétaire, les vignobles ont conservé leurs noms pittoresques: "Clos des Abbayes», "Clos des Moines», "Abbaye du Mont». La chronique a gardé le souvenir du frère Antoine qui planta en l'année 1150 le «Clos de Embleyres». D'autres moines vignerons défrichèrent les «Faverges» où s'établit l'abbaye d'Hauterive. Le Canton de Fribourg exploite aujourd'hui ce vignoble dont il hérita des cisterciens quand il les chassa.

Le Jura qui borde à l'ouest la Suisse occidentale est fortement boisé et voué à l'élevage. Le Mont Tendre culmine à 1683 mètres, suivi de près par la Dôle qui atteint 1680 mètres, et au pied de laquelle se trouve Bonmont, la première abbaye cistercienne de Suisse.

Le Moyen Pays est creusé par les vallées de la Broye, de la Sarine et de l'Aar. C'est un pays de prairies et d'élevage où l'on trouve les autres abbayes: Hauterive, dans une boucle de la Sarine, Frienisberg, à l'écart de la rive droite de l'Aar, au pied de l'Aarlberg. Tetligen, plus proche de la rivière, sur le versant sud-ouest, et Fraubrunnen, non loin de la rive gauche de l'Emme. Ces trois monastères sont de langue germanique. Deux abbayes de femmes, Bellerive et

14 Vita Bernardi, lib. I, cap. II, n. ${ }^{\circ} 4$. 
Bellevaux, ont disparu sans laisser de trace autre que leur nom. La première se trouvait sur la rive orientale du Léman, au nord de Genève. La seconde était au nord de Lausanne, dans une étroite vallée. La Fille-Dieu, aux portes de Romont, ne se distingue en rien par son site. Plus heureuse que Bellevaux et Selnau, comme elle dans un faubourg de ville, elle dut à un hasard de la guerre de pouvoir subsister jusqu'à nos jours. La Maigrauge se trouve dans une boucle de la Sarine, en face de la ville de Fribourg.

\section{Suisse médiane}

Centre historique et géographique de la Confédération, la Suisse médiane englobe les Cantons du Tessin, d'Uri, d'Unterwald, de Schwyz, de Glaris, de Lucerne, de Zurich, d'Argovie, de Bâle et le nord de celui de Soleure. Le Lac des Quatre-Cantons, allongé, sinueux, prolongé par les vallées de l'Aar, de la Reuss (Vallée de l'Urseren entre les massifs de l'Urner Alpen et du Glarner Alpen, voie d'accès au Saint-Gotthard), de la Klasen et de la Muota, est le coeur de la Confédération. Les petites cités de cette «Vieille Suisse» conservent le souvenir des luttes des gens des Vallées pour conquérir et maintenir leur indépendance. Altdorf, au sud du lac d'Uri et chef-lieu du Canton de ce nom, est immortalisé par la légende de Guillaume Tell. Schwyz conserve l'original du Pacte de 1291. A Brunnen, Morgaten, Sempach et Kappel, de part et d'autre du lac, eurent lieu les batailles décisives. On y trouve encore les deux principautés monastiques d'Einsiedeln et d'Engelberg. Pour tenir la route qui, par la Reuss, le Lac et le Saint-Gothard, unissait l'Alsace et le Duché de Bade à l'Italie, et celle qui, par la vallée de la Limmat, le Zürichsee et le Walensee, évitait la boucle du Rhin, les Habsbourg construisirent la forteresse qui a conservé leur nom au nord du pays d'Argovie. Le tourisme et l'industrie ont fait la richesse de cette région.

Les abbayes cisterciennes se sont installées à l'écart dans la plaine alluviale et dans les vallées largement ouvertes au nord du Lac. On trouve ici les deux plus importants monastères de moines: Wettingen, à la lisière sud de la cité industrielle qui s'est construite près de Baden et qui porte son nom, et Sant Urban, demeuré isolé sur la rive droite d'un modeste sous-affluent de l'Aar, à la jonction de deux vallées. Kappel, fille d'Hauterive en pays germanique, à l'endroit où Zwingle trouva la mort, est la plus solitaire des trois abbayes d'hommes, entre la Reuss et le Zürichsee.

Le groupe des abbayes féminines de cette partie médiane est le plus important du pays. Deux d'entre elles, Engenthal, ainsi nommée de par sa situation dans une étroite vallée, et Olsberg, avoisinent la rive gauche du Rhin. Selnau était un monastère urbain sous les murs de la vieille ville de Zurich. Il a disparu entièrement aujourd'hui, mais un quartier de la cité conserve son nom. 
Steinen, qui vivota et disparut de lui-même, correspond à une petite ville industrielle. Rathausen, beaucoup plus important, se trouve à peu de distance de Lucerne, mais suffisamment isolé comme La Maigrauge et la Fille-Dieu. Eschenbach qui existe encore est sis dans une modeste localité à un carrefour de routes. Toutes les autres sont demeurées à l'écart. Leur implantation dans des Cantons demeurés catholiques leur a valu de durer pour la plupart jusqu'au XIX' siècle, sauf Engenthal et Olsberg balayées par la Réforme. A ces monastères on peut adjoindre Mariazell-Wurmsbach, dans le Canton de Saint-Gall, que sa position sur la rive du Zürichsee permet de rattacher à la Suisse médiane.

\section{Suisse orientale}

De la Suisse orientale qui groupe les Cantons des Grisons, de Saint-Gall, des deux Appenzell, de Thurgovie et de Schaffhouse, seuls nous intéressent ceux de Saint-Gall et de Thurgovie. L'abbaye féminine de Feldbach échappe à toute classification par sa situation exceptionnelle sur un éperon rocheux de la rive méridionale de l'Untersee, l'une des deux branches du lac de Constance. Par son site, il s'apparente à Bellerive, sur le Léman, et à MariazellWurmsbach, sur le Zürichesee. Comme ce dernier monastère, il s'agit d'un couvent de béguines incorporé à l'Ordre. Kalchrain et Tänikon, situé sur le même axe au nord et au sud de Frauenfeld, étaient installés dans les larges vallées de la Thurgovie, au climat tempéré par l'action du lac de Constance, pays de grasses prairies et de riches vergers. Magdenau, dans le Canton de Saint-Gall, entre deux groupes peu élevées, à l'endroit où la Thur sortant du Toggenburg inflèchit à l'est son cours, bénéficie lui aussi, du moins dans une certaine mesure, de l'influence du climat particulier de la Thurgovie. Ces monastères n'eurent guère à souffrir jusqu' au siècle dernier des luttes religieuses. Magdenau a réussi à durer jusqu'à nos jours, tandis que les trois abbayes de Thurgovie disparurent en XIX' siècle et se regroupèrent dans le Vorarlberg autrichien.

Au terme de ce bref aperçu géographique, nous croyons devoir rappeler ce que nous écrivions dans notre étude sur les monastères de la péninsule ibérique: le site commande le déloppement de chaque abbaye. Il est inutile de vouloir comparer entre eux deux établissements cisterciens même très rapprochés. Nous avions pris comme exemple les monastères de Poblet et de Santes Creus, en Catalogne, dont l'un, Poblet, le plus important, est demeuré absolument isolé, alors que Santes Creus a donné naissance à un peuplement, et nous écrivions: «Ces deux exemples -mais on pourrait les multiplier- suffisent pour démontrer qu'on ne peut tirer de conclusions générales, mais que chaque monastère est un cas d'espèce qui demande à être étudié comme tel». Ceci 
s'applique aussi aux monastères de la Suisse. Ce qui ressort de ce bref aperçu géographique, c'est la dispersion des abbayes cisterciennes masculines et féminines sauf dans la région historique. Leur isolement n'est pas absolu. Recherchant les vallées ouvertes vers le nord, assez proches des villes, dans une région, le Plateau, où la densité de la population était assez élevée, ils peuvent se développer harmonieusement. Si les circonstances historiques ont brutalement fait disparaître une bonne moitié des abbayes au XVI' siècle, celles qui ont survécu jusqu'au XIX', comme Wettingen et Sant-Urban, faisaient grandement honneurr à l'Ordre de Cîteaux.

\section{IMPLANTATION DES ABBAYES}

L'influence de Clairvaux s'est étendue sur une partie de la Savoie, les pays du Léman et en Franche-Comté. La "carte de la filiation de Clairvaux" "situe en Romandie les trois monastères de la filiation claravallienne pendant la brève période de peuplement intensif de la Suisse: 1131-1143. Kappel, en Suisse allemanique, ne doit pas être pris en considération. Comme Wettingen, dans la lignée de Morimond, il s'agit d'une fondation tardive faite à une époque où l'influence des chefs de filiation ne se fait plus sentir.

Nous avons vu qu'il y avait d'étroites affinités entre la Bourgogne et l'actuel Pays de Vaud parfois désigné sous le nom de Bourgogne transjurane. Nous pouvons considérer l'expansion cistercienne dans cette région comme liée au peuplement bourguignon. Les grandes familles du Pays de Vaud étaient apparentées à celles de Bourgogne dont était issu saint Bernard. L'abbé de Clairvaux se rattachait aux Grancey par son aïeule Eve de Grangey ${ }^{16}$. Monsieur Jean Richard a démontré combien est imprécise la généalogie de saint Bernard ". Il note cependant que «la parentèle de saint Bernard lui assurait d'emblée de précieux appuis; l'illustration de son lignage maternel lui permettant de traiter d'égal à égal avec les barons» ${ }^{18}$. Ces liens de parenté semblent avoir favorisé la pénétration de Clairvaux dans le Pays de Vaud. Guy de Maligny, cousin de Bernard, devint évêque de Lausanne en 1130. Il apparaît dans l'acte de fondation de l'abbaye d'Hauterive. Son successeur, Amédée, ancien moine de Clairvaux puis abbé d'Hautecombe, sur le lac du Bourget, était un disciple de Bernard. D'autres liens existaient avec les Faucigny dont

1) Cf. le tableau du peuplement cistercien de la Suisse, fig. I.

${ }^{16}$ Il ne s'agit que d'une "tradition respectable», mais qui semble assez convaincante à l'abbé Chaume. Cf. Les origines familiales de saint Bernard, dans Saint Bernard et son temps, Dijon, 1927, I, p. 93.

15.

${ }^{17}$ Jean Richard, Le milieu familial, dans Bernard de Clairvaux, Paris, 1953, p.

${ }^{18} \mathrm{Ib} ., \mathrm{p} .15$. 
l'un, Gérard, fut évêque de Lausanne de 1107 à 1129, et l'autre, Arducius, d'abord Prévôt de Lausanne, devint évêque de Genève en 1135 . Nous voyons, d'autre part, l'abbé de Clairvaux intervenir en 1132 dans les affaires de Genève et ménager une entrevue entre Conrad de Zahringen, «Recteur des deux Bourgognes», et son adversaire le comte Amédée de Genevois. La réputation de saint Bernard, la vénération dont il était entouré, ses attaches familiales, ses contacts avec les prélats du Pays de Vaud, suggèrent pourquoi le premier établissement cistercien appartenait à sa filiation.

Dans le diocèse de Genève plusieurs des maisons bénédictines de la Congrégation de Molesme acceptèrent la règle de Cîteaux. Aulps avait été fondée en 1904. Elevée au rang d'abbaye en 1096, elle avait essaimé à Hautecombe en 1101. Le prieuré de Bonmont, au pied de la Dôle, à quelques kilomètres de Nyon, avait été fondé en 1123 par Gauthier et Étienne de Divonne. Ceux-ci l'avaient peuplé avec des moines bénédictins venus de Balerne, abbaye créée en 1107 dans l'actuel département du Jura ${ }^{19}$.

\section{Monastères de moines}

Il est possible que l'affiliation de Bonmont soit le résultat de la correspondance échangée entre l'abbé de Clairvaux et le nouvel évêque de Lausanne Guy de Faucigny, son cousin. Le rôle de celui-ci n'est pas clairement attesté dans cette affaire. On constate simplement que les bénédictins de Bonmont furent affiliés le 7 juillet 1131 et placés dans la dépendance immédiate de Clairvaux. Ceux de Balerne qui avaient peuplé Bonmont ne devinrent cisterciens qu'un peu plus tard, en 1136. C'est aussi en 1136 que furent affiliés Aulps et Hautecombe. Clairvaux fonda Chézery, dans la même région, en 1140. Entre temps une autre filiale française de Clairvaux, Cherlieu, avait pris pied en Romandie ${ }^{20}$.

Ce monastère avait déjà fondé Acey en $1136^{21}$, année de l'affiliation d'Aulps, de Balerne et d'Hautecombe. Un peu auparavant, vers 1134, Guy de Maligny et le comte Amédée de Blonay avaient donné à Cherlieu le lieu dit Hautcrêt à une dizaine de kilomètres au nord du Léman. La nouvelle abbaye fut consacrée le 14 mars 1143 . Cette année est communément acceptée comme celle de san fondation.

Un événement tragique est à l'origine de la fondation d'Hauterive. Le

19 Arr. de Poligny, ct. de Champagnole, cm. de Mont-sur-Marnet. Sur la rive gauche d'un affluent de l'Ain.

${ }^{20}$ Haute-Saône, arr. Ve soul, ct. Vitrey, cm. Montigny-lès-Cherlieu. Filiation de Clairvaux, fondé en 1131.

${ }^{21}$ Occupé aujourd'hui par les cisterciens de la Stricte Observance. Jura, arr. Dôle, ct. Gendrey, cm. Vitreux. 
comte Pierre de Glâne et son fils Ulrich avaient été assassinés dans l'église de Payerne. Son frère Guillaume, dernier survivant de la famille, se réfugia en France. Il décida de fonder un monastère et de s'y retirer. Il s'adressa à l'abbé de Cherlieu qui envoya douze moines conduits par Gérard, premier abbé, dans une boucle de la Sarine, un peu au sud de l'endroit où devait s'élever plus tard la ville de Fribourg, au lieu dit Hauterive. La prise de possession eut lieu le 25 février 1138. Guillaume de Glâne y mourut sous l'habit de convers le 11 février 1143. Astrolabe, l'un des douze moines venus de Cherlieu et qui devint ensuite abbé d'Hauterive aurait été, pense-t-on, le fils d'Abélard et d'Héloïse.

Toutes ces fondations et affiliations semblent bien dues à l'influence de saint Bernard. Bernard Bligny ${ }^{22}$ y voit le résultat du premier voyage de l'abbé de Clairvaux en Italie en 1133. Deux ans plus tard Bernard séjourna à Aulps et y revint probablement en 1136, année de l'affiliation de ce monastère. Ce fut un Claravallien, Bouchard, qui fut envoyé à Balerne, et un autre, Amédée le jeune, futur évêque de Lausanne, à Hautecombe. Dans une de ses lettres, l'abbé de Clairvaux recommande les moines de Bonmont et d'Hautecombe à l'évêque de Genève, Arducius de Faucigny ${ }^{23}$. La tactique de Bernard, dans la plupart des cas, consiste en une substitution d'influence. La règle cistercienne supplante l'observance bénédictine. Nous avons eu l'occasion de le remarquer en traitant des abbayes de Galice et du nord du Portugal ${ }^{24}$. Il serait intéressant de relever dans l'ensemble de la filiation de Clairvaux du vivant de saint Bernard le nombre des affiliations et de les comparer avec celles de la lignée de Morimond.

Ce dernier monastère n'intervient pas directement en Suisse. Comme en Espagne où il pénétra par l'intermédiaire de ses filiales du sud de la France, c'est par l'abbaye de Bellevaux " ${ }^{23}$ qu'il se manifesta. Celle-ci, première fille de Morimond, avait fondé Lucelle au diocèse de Bâle en 1124. Ce monastère qui occupe une place de choix dans la lignée de la quatrième fille de Cîteaux constitue «le deuxième jalon de la pénétration vers l'Europe centrale»" ${ }^{26}$ après Kamp, au diocèse de Cologne, fondé en 1123 . Bellevaux affilia le 24 mai 1135 le dernier monastère de la Suisse romande, Montheron, fondé en 1128 à la lisière du bois du Jorat par l'évêque Gérold de Faucigny. Lucelle inaugura les fondations en Suisse allémanique avec Frienisberg, le 15 mai 1138. Hauterive,

${ }^{22}$ Bernard BLIGNY, L'Église et les ordres religieux dans le royaume de Bourgogne aux XI' et XII siècles, Paris, P.U.F., 1960, pp. 350 et suiv.

23 Patrologie Latine, 182, col. 132.

24 L'implantation des abbayes cisterciennes, $1^{\text {ere }}$ partie.

${ }^{25}$ Fondée en 1120, dans la Haute-Saône, arr. de Vesoul, ct. Réoz, cm., Cirey-lèsBellevaux.

26 Bernard BLIGNY, L'Église et les ordres religieux, p. 357. 
à son tour, envoya, le 29 juin 1185 , un groupe de moines peupler le monastère de Kappel fondé dans le Canton de Zurich par Konrad von Eschenbach. Une autre filiale de Lucelle, Sant Urban, dans le Canton de Lucerne, d'abord établie à Kleinroth (Canton de Berne) en 1194, puis transférée en ce lieu l'année suivante, clôt la liste des fondations cisterciennes du XII ' siècle. Salem, abbayefille de Lucelle ${ }^{27}$ peuplait, le 14 octobre 1227, le monastère de Wettingen, dans le Canton d'Argovie, fondé par le comte Henri de Rapperswild qui devait y mourir en 1246 sous l'habit cistercien. Il faut attendre ensuite les premières années du XVI ' siècle pour voir apparaître un modeste prieuré fondé comme lieu de refuge par les moiners de Lucelle, en 1505, dans une enclave du Canton de Soleure dans celui de Berne. Baptisé Kleinlutzel (Petite Lucelle) par opposition à sa mère dite en allemand Grosslutzel (Grande Lucelle), il n'eut jamais beaucoup d'importance.

\section{Monastères de religieuses}

La fondation d'abbayes de religieuses cisterciennes et les affiliations ne commencèrent que dans la première moitié du XIII ' siècle. En fait, presque tous ces monastères sont des affiliations. Comme il arrivait souvent, des moniales ou de pieuses femmes, des Béguines, demandaient après un certain temps leur rattachement à l'Ordre de Cîteaux. Ceci complique parfois la chronologie car, même avant d'avoir été acceptées par le Chapitre général, ces religieuses n'hésitaient pas à se prévaloir de leur appartenance à l'Ordre.

On admettait jusqu'à présent que trois de ces abbayes étaient cisterciennes depuis le XII ' siècle: Kleinlutzel (1136/1138), Bellerive (vers 1150) et Olsberg (affilié vers 1180). Les études récentes de Georg Boner auxquelles vous renvoyons dans la bibliographie jointe à la notice de chaque monastère permettent de corriger cette chronologie inexacte.

Le monastère de Gottesgarten (Hortus Dei) fut fondé aux environs de 1230 dans le Canton de Berne, probablement à Kleinroth. Ulrich von Langenstein avait déjà établi à cet endroit un monastère de moines en 1194. Mais, dès l'année suivante, les religieux se transportèrent à trois kilomètres au nord et y bâtirent l'abbaye de Sant Urban. Il en fut de même pour les moniales qui, en 1236, abandonnèrent Kleinroth pour aller s'installer dans le Canton d'Argovie, à 800 mètres à l'ouest de la petite cité d'Olsberg. C'est sous ce nom que Gottesgarten fut désormais connu. À la suite de Georg Boner, il ne nous paraît pas possible de considérer Kleinlutzel comme un monastère de religieuses

27 Salem, ou Salmansweiler, fondé en 1136 par Guntram von Adelsreute, peuplé par des moines de Lucelle le 15 mai 1138. Dans le Pays de Bade, Kreis Überlingen, à 9 km à l'est de cette ville. 
cisterciennes peuplé seulement de 1136 à 1138 . Des chanoines réguliers s'y seraient établis aux environs de 1190. En 1486 des Augustines leur auraient succédé jusqu'en 1498, date à laquelle des cisterciens venus de Lucelle les auraient remplacées ${ }^{28}$. En fait, c'est en 1505 que les cisterciens de Lucelle éprouvèrent le besoin de s'aménager un refuge et choisirent l'ancien couvent de chanoines qu'ils conservèrent jusqu'en 1790.

L'abbaye de Frauenthal fut fondée dans le Canton de Zug par Ulrich von Schnabelburg et son épouse Agnes (ou Adélayde) von Eschenbach à une date assez difficile à préciser. Humer indique 1231 , mais il semble que ce serait plutôt en 1240. Canivez ${ }^{29}$ a édité un statut du Chapitre général de 1244 que nous traduisons: "L'inspection de l'abbaye de moniales de Vallis Sanctae Mariae, au diocèse de Constance, que le Seigneur Pape ordonne d'incorporer à l'Ordre, est confiée aux abbés de Lucelle et de Kappel...». Le Catalogus ${ }^{30}$ maintient la date de 1231 pour la fondation et fixe l'incorporation à l'année 1253 , sous la paternité de l'abbé de Kappel ${ }^{31}$. Nous nous en tenons aux indications du statut de 1244.

Magdenau, dans le Canton de Saint-Gall, avait été fondé le 3 avril 1244 par Rudolf Giel von Glattburg et son épouse Gertrude. Le Chapitre général de 1247 confie aux abbés de Salem (Bade) et de Pairis (Alsace) l'inspection de ce monastère que l'Ordre accepte à la demanda du pape ${ }^{32}$.

Fraubrunnen, dans le Canton de Berne, fut fondé en 1246 par le comte de Kyburg. Au sujet de l'incorporation de ce monastère, le Chapitre général fit montre de son habituelle sévérité quand il s'agissait de préserver ses droits. L'inspection de l'abbaye avait été confiée aux abbés d'Hauterive et de Frienisberg en $1249^{33}$. Fraubrunnen était placée dans la dépendance de Frienisberg. Mais nous apprenons, l'année suivante, que les deux abbés avaient procédé à l'incorporation contre la volonté du Chapitre ou sans tenir compte de la procédure régulière (contra statuta Capituli generalis). Par égard pour l'excellen-

28 Paul STINTZI, Aus des Geschichte des Klösterleins Kleinlützel, dans Jurablatter, Monatsschrift für Heimat - und Volkskunde des Raurachers, 1957, pp. 49-53.

${ }^{29} \mathrm{~J}$. CanIveZ, Statuta Capitulorum Generalium Ordinis Cisterciensis, Louvain, 1933 et suiv., II, an. 1244, n. $^{\circ} 54$.

${ }_{30}$ Catalogus Generalis Abbatiarum, Prioratuum, Monasteriorum et Personarum religiosarum... S. Ordinis Cisterciensis, Rome, 1954. Nous citerons simplement dans le texte et en note, Catalogus.

${ }^{31}$ Catalogus, notice de Frauenthal, p. 313.

32 Statuta, II, p. 323, n. ${ }^{\circ}$ 43. Canivez traduit à tort le mot Maginowe employé dans le statut pour désigner le monastère par Maigrauge (ib., note 7: «Magerowe [sic], Maigrauge, in Helvetia, prope Friburgum "). La Maigrauge n'existait pas encore et n'appartint jamais au diocèse de Constance mentionné dans le statut 43.

${ }^{33}$ Statuta, II, p. 339, n. 26. 
te réputation des deux coupables, ils ne furent pas déposés (licet de iure Ordinis deberent deponi), mais simplement punis. De surcroît, le Chapitre refusa de s'occuper pendant un certain temps du monastère de Fraubrunnen ${ }^{34}$.

Tanikon, dans le Canton de Thurgovie, avait été fondé en 1249 sous le patronage de sainte Anne par Eberhard von Bichelsee. Il fut incorporé à Cîteaux en 1255 ou 1256, à la demande de Philippe de Savoie, archevêque de Lyon, et de la comtesse de Fribourg. Canivez commet une erreur en le confondant avec le monastère de Lilienthal visité en 1246 et soumis à la paternité de Kaisersheim. Tanikon n'existait pas à cette date ". Cette confusion résulte de la similitude des noms latins de ces deux monastères: Vallis lilii et Vallis lilium. Le Chapitre accepta d'incorporer Tanikon en 1266 et le plaça dans la filiation de Wettingen ${ }^{36}$.

Rathausen fut à l'origine une petite communauté de Béguines installées en 1245 à Ennethorw, à cinq kilomètres environ au sud de Lucerne. Elles se transportèrent presque aussitôt à Riedholz, un peu au nord de la ville, dans une propriété que leur donna un certain Pierre Schnyder, bourgeois de Lucerne. Ces Béguines adoptèrent les usages de Cîteaux en 1251 et c'est à cette occasion qu'elles changèrent le nom de Riedholz en celui de Rathausen. Le Chapitre général fit inspecter le monastère en 1260 et le soumit à l'abbé de Lucelle ${ }^{37}$. Celui-ci fit transférer en 1266 la paternité de l'abbaye à l'abbé de Sant Urban.

On ne sait presque rien de l'origine de Bellerive, sur le bord du Léman. Ce monastère n'aurait pas été fondé en 1150 par Gérold de Langin, comme on l'admettait, mais vers 1254 ou 1256. La liste des abbesses confirme cette opinion puisque la plus ancienne connue, Elisabeth $I^{\text {tere }}$, gouverna jusqu'en 1269. Il est possible que Bellerive ait été incorporé en 1254 si l'on applique à cette abbaye un statut du Chapitre général de cette année prescrivant aux abbés d'Aulps et de Bonmont de visiter «les deux abbayes filles de Bonmont réduites à la pauvreté et de les fondre en une seule»" ${ }^{38}$.

Le plus ancien document concernant l'abbaye de la Maigrauge est une donation faite le 3 juillet 1255 par le curé de Tafers à des religieuses d'un terrain sur le bord de la Sarine. La petite communauté adopta la règle de saint Benoît. Elle fut incorporée à Cîteaux le 31 juillet 1261. Canivez a confondu ce monastère avec celui de Selnau ${ }^{39}$. Le texte, d'ailleurs très bref, du statut,

34 Statuta, II, p. 352, n. 32.

35 Statuta, II, p. 314, n. 64 et note 4.

36 Statuta, III, p. 42, n. 33.

37 Statuta, II, p. 473, n. 59.

38 Statuta, II, p. 406, n. 30.

39 Statuta, II, p. 485, n. $^{\circ} 46$, et p. 486 , note 1: «Augia sancta, ut videtur, i.e. Seldenau, in Helvetia...». 
stipule que les abbés de Bonmont et d'Hautcrêt visiteront le monastère de Augia qui sera placé dans la filiation d'Hauterive. La localisation géographique des trois monastères masculins cités dans le statut nous ramène au Pays de Vaud et à la région de Fribourg alors que Selnau (ou Seldenau) était aux portes de Zurich. Le mot latin Augia employé ici absolument est à l'origine de cette confusion. On ne spécifie pas s'il s'agit d'Augia ancillarum ou virginarum (Magdenau), d'Augia macra, Macraugia (La Maigrauge) ou d'Augia sancta (Seldenau). Nous retrouverons d'ailleurs Selnau un peu plus loin.

Un autre petit couvent de Béguines donna naissance à l'abbaye de Mariazell-Wurmsbach, dans le Canton de Saint-Gall. Elles succédèrent en 1259 à des religieuses établies à Oberbollingen, non loin du site actuel. Ces Béguines adoptèrent la règle de Cîteaux en 1261. Le Chapitre général de cette année en confie l'inspection à l'abbé bénédictin de Saint-Gall et aux abbés cisterciens de Sant Urban et de Wettingen, et place la nouvelle abbaye dans la filiation de Lucelle ${ }^{40}$. De son côté le Catalogus "1 date l'incorporation en 1262 à la demande des abbés de Lucelle, de Frienisberg, de Sant Urban et de Wettingen. Mariazell-Wurmsbach aurait été placé dans la filiation de Kappel jusqu'en 1363, année où le monastère fut soumis à Wettingen. La contradiction entre Canivez et le Catalogus n'est qu'apparente. L'abbé de Lucelle s'était vu confier les deux abbayes de Rathausen et de Mariazell-Wurmsbach, mais il demanda au Chapitre général de 1266 d'en être déchargé ${ }^{42}$. L'abbé de Sant Urban en hérita. Par la suite Mariazell-Wurmsbach fut confié à Kappel, monastère plus proche.

Selnau, souvent orthographié Seldenau, fut fondé en 1256 par Adèle von Küssnacht pour des chanoinesses de Saint-Augustin. On admet qu'il fut affilié à Cîteaux en 1264. Le Chapitre le fit visiter cette année-là. Les religieuses -et le cas n'est pas rare- durent adopter plus tôt la règle de Cîteaux car elles $s^{\prime}$ intitulent, dans une charte de 1259 , «sorores ordinis sancti benedicti secundum constitutiones cistercienses".

Des Béguines encore, installées vers 1253 , pense-t-on, à Steinen, au nord de Schwyz, furent affiliées à Cîteaux en $1267^{43}$.

La Fille-Dieu, près de Romont, fut fondée en 1268 par trois soeurs, Juliette, Pernette et Cécile de Villaz, et placée dans la dépendance d'Hautcrêt

40 Statuta, II, p. 485, n. 46.

${ }^{41}$ Catalogus, p. 235, notice sur Mariazell-Wurmsbach.

42 Statuta, III, p. 44, n. ${ }^{\circ} 46$.

${ }^{43}$ Cette chronologie nous semble la plus probable. Canivez (Statuta, II, p. 366, n." 34) a mal traduit le mot Stanlbero du statut de l'année 1251 par Steinen. Stanlbero est certainement un monastère allemand si l'on en juge par les abbés enquêteurs désignés par le Chapitre, ceux de Kaisersheim et d'Alderspach, en Bavière, et de Salem, dans le Duché de Bade. 
jusqu'à la suppression de ce monastère en 1536. La paternité en fut alors confiée à Hauterive de 1593 à 1848. Cette abbaye appartient aujourd'hui à la Stricte Observance de Cîteaux.

L'année suivante le comte de Homburg fondait Engenthal, la «Vallée etroite», dans le diocèse de Bâle. En 1274, des religieuses venues de Rathausen peuplèrent le monastère d'Ebersecken, dans le Canton de Lucerne, fondé par Rudolf von der Balm et Jakob von Fischlbach. On ignore tout de la fondation de Tetligen, au Canton de Bern. Le plus ancien document connu mentionnant l'observance cistercienne est daté du $1^{\text {" }}$ janvier 1284.

Nous sommes mieux renseignés au sujet de Bellevaux, abbaye sise au nord de Lausanne, mais qui a complètement disparu. Elle fut fondée en 1267 par le chevalier Bertold Bevroz pour des religieuses dont la règle n'est pas précisée clairement. On suppose qu'elles observaient celle de Prémontré. Elles furent incorporées à Cîteaux en 1293.

La date d'affiliation de Gnadenthal est difficile à préciser. On trouve des Béguines ou des Clarisses en cet endroit vers 1282. Elles furent placées officiellement sous la dépendance de l'abbé de Wettingen en 1318, mais elles se disent déjà cisterciennes en 1305 et en 1313. Un document de 1310 nous apprend qu'elles sont «des Ordens von Citel» (sic). À en juger par les statuts du Chapitre général, elles n'auraient été réellement incorporés qu'en 1394. Cependant les quelques documents connus par ailleurs ne précisent jamais la règle observée par ces religieuses avant l'incorporation de 1394, à l'exception des trois que nous venons de citer.

C'est aussi pour des Béguines que Walter et Ulrich von Hohenklingen bâtirent un couvent à Kalcbrain vers 1230. Elles furent affiliées à l'Ordre en 1328.

Le dernier monastère de cisterciennes que nous trouvons en Suisse est celui d'Eschenbach, dans le Canton de Lucerne, fondé en 1285 par les barons d'Eschenbach Walter III et son frère Berthold pour des Chanoinesses de Saint-Augustin. Ce n'est qu'en 1588 qu'il fut incorporé à la Congrégation cistercienne de Haute-Allemagne et placé sous l'autorité de l'abbé de Sant Urban. Clément VIII confirma cette affiliation le 5 mai 1594. L'année suivante, le 17 avril 1595, Dom Edme de la Croix, abbé de Cîteaux, érigea le monastère en abbaye.

\section{Chronologie des monastères}

Si nous adoptons comme base de notre chronologie l'année de l'incorporation à l'Ordre de Cîteaux, sans prendre en considération celle de la fondation pour un autre Ordre religieux, la table des monastères cisterciens se présente comme suit: 


\begin{tabular}{|c|c|}
\hline $\begin{array}{l}\text { Lucelle } \ldots \ldots \\
\mathbf{1} \text { - } \\
\text { 2 } \text { - } \text { - Monmontheron } \\
\text { 3 }\end{array}$ & $\begin{array}{l}25 \text { mars } 1124 \\
7 \text { juillet } 1131 \\
24 \text { mars } 1135 \\
25 \text { février } 1138 \\
15 \text { mai } 1138 \\
14 \text { mars } 1143 \\
29 \text { juin } 1185 \\
1194 \\
1226\end{array}$ \\
\hline
\end{tabular}

\begin{tabular}{|c|c|}
\hline 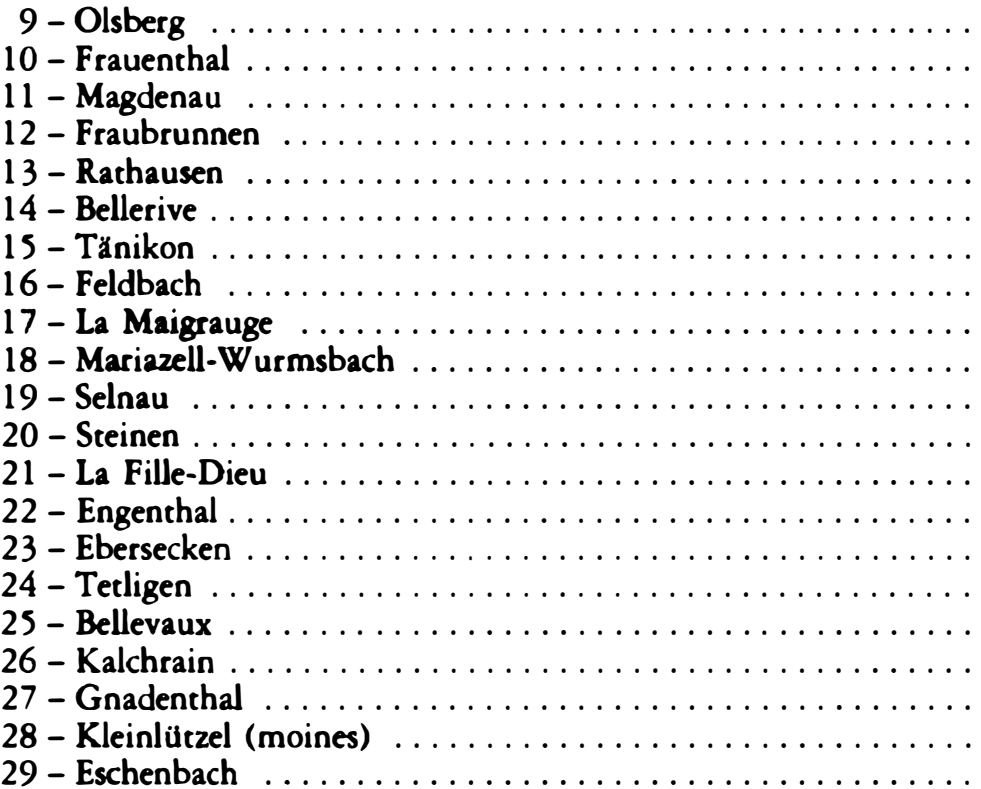 & $\begin{array}{l}1230 / 1235 \\
1231 / v \cdot 1240 \\
3 \text { avril } 1244 \\
1246 \\
1251 \\
1254 / 1256 \\
1255 / 1256 \\
1256 \\
31 \text { juillet } 1261 \\
1263 \\
1264 / 1265 \\
1267 \\
1268 \\
1269 \\
1274 \\
1284 \text { (?) } \\
1293 \\
19 \text { mai } 1328 \\
1394 \\
1505 \\
24 \text { février } 1588\end{array}$ \\
\hline
\end{tabular}

\section{Les abbayes jusqu'au XX' siècle}

Nous avons déjà signalé au passage, dans la première partie de cette étude, les principales suppressions d'abbayes. Il n'y a pas lieu ici de retracer l'histoire de chacune d'elles. Les chroniques nous font part, surtout, des déprédations commises par les armées en campagne. Les moines de Lucelle doivent se réfugier en 1505 à Kleinlützel. Ils sont de nouveau contraints d'abandonner leur monastère au cours de la Guerre de Trente Ans. Après une absence de 25 ans (1632-1657), ils y rentrent, mais l'abbaye est brûlée en 1699. Kappel connaît l'épreuve en 1413 quand les Confédérés (Eidgenossen) la ravagent. Fraubrunnen est incediée deux fois, en 1260 et en 1375. Ce sont là, si l'on peut se permettre de porter un jugement qui peut sembler un peu cavalier, des faits mineurs dans l'histoire séculaire d'une abbaye. Nous ne citerons qu' un épisode qui suffira pour montrer combien était parfois précaire la situation des religieuses. Il s'agit de la destruction de Bellerive, le 7 octobre 1530, relatée de la manière suivante par Jeanne de Jussy: 


\begin{abstract}
Aucuns meschans garçons de Genève prindrent une compagnie de ces Suisses et les menèrent au monastère de Belle-Rive des Dames de Cisteaux, près de Genève, pour les fourrager; ils n'y laissèrent rien et emportèrent tout jusqu'à la cloche de l'église (elle est maintenant encore dans les tours de Saint-Pierre de Genève) et puis y mirent le feu; mais Notre-Seigneur y ouvra si bien que jamais le feu ne put prendre à l'église, mais demeura en son temps malgré eux. Les pauvres dames religieuses se sauvèrent, en habits dissimulés, pauvres esgarées, chacune en la maison de leurs parents, et après se rassemblèrent en leur monastère pour servir Dieu comme devant 4 .
\end{abstract}

La suppression des monastères par la Réforme, quelle que soit la secte dominante, est un fait qui ne peut échapper à l'attention de l'historien. Dans une étude parfaitement documentée et menée avec toute l'objetivité désirable, le chanoine Cristiani "s analyse les caractères dominantes de la Réforme protestante. Nous ne pouvons faire mieux que le citer: «Un trait commun également à toutes les sectes est d'avoir été antimonastiques, car toutes elles ont réprouvé l'idéal monastique, toutes elles ont fait du pillage et de la suppression des couvents et du transfert de leurs biens à l'État ou à la collectivité laïque l'un des premiers devoirs de la «Réforme» (col. 2029)». Cette suppression et la spoliation qui l'accompagne sont des faits logiques. Pourquoi? Cristiani en donne les raisons: "C'est la mystique pariculière de la «Réforme» qui a déterminé la chute de l'idéal monastique et ouvert la porte aux convoitises des pouvoirs civils à l'égard des biens importants, constituant une main-morte considérable, que l'orientation économique nouvelle désirait secrètement remettre en circulation, ou que les princes voulaient utiliser pour se couvrir des finances trop souvent obérées par des besoins nouveaux. Le caractère antimonastique de la Réforme est donc un caractères dérivé et secondaire. Les moines devaient disparaître ${ }^{46}$, soit parce qu'on les considérait comme les suppôts du Siège romain, soit parce que leur vie était en contradiction avec le principe de la justification par la foi seule, sans les oeuvres, soit parce que leurs propriétés étaient le point de mire d'ambitions d'ordre politique, financier et économique, suivant les cas (col. 2020)». Cette analyse lucide dun des caractères distinctifs de la Réforme est à retenir. Partout où la nouvelle religion supplantera l'orthodoxie romaine, les mêmes causes produiront les mêmes effets. Il importe peu que l'évolution de la pensée religieuse au sein des diverses sectes protestantes ait abouti de nos jours à l'acceptation, ou simplement à la tolérance, de communautés réformées au caractère monastique plus ou moins affirmé. L'historien n'a pas à prendre en considération un phénomène qui se produit quatre siècles après l'apparition d'une idéologie qui fut néfaste por

${ }^{44}$ Jules VUY, Jeanne de Jussy et les soeurs de Sainte-Claire, Genève, 1881, p. 14.

4s L. CRISTIANI, art. Réforme, dans Dictionnaire de Théologie Catbolique, XIII, 2e partie, Paris, 1937. Nous renvoyons aux colonnes 2028 à 2030: III - Thèse bistorique.

46 Souligné par nous. 
l'institution monastique sous toutes ses formes. Seuls comptent les faits, et ils sont indéniables. L'implantation de la Réforme dans une région est immédiatement suivie de la dissolution des monastères. Il s'agit d'un principe appliqué avec une rigoureuse logique et poussé à ses conséquences extrêmes. Notons tout de suite qu'il en ira de même des doctrines révolutionnaires et du radicalisme. Ce que nous appelons sectarisme n'est souvent que froide logique.

Cette suppression n'est pas nécessairement sanglante comme il arrivera dans les Pays-Bas, par exemple, où nous verrons des monastères incendiés après pillage et leurs habitants massacrés. Voyons comment les choses se sont passées lors de la suppression de l'abbaye féminine de Bellevaux près de Lausanne. Ce monastère ne comptait que cinq religieuses en 1536. Il n'était pas riche. On ne peut donc soupşoner les édiles de Lausanne d' avoir voulu renflouer le budget de la ville avec les maigres revenus de la petite abbaye. Il ne semble pas, non plus, que la préssence de cinq inoffensives religieuses, dont certaines étaient âgées, ait été un danger pour la «Réformation». Tout se passe avec correction, sinon avec la courtoisie qui convient à des gens de bien. Le 13 septembre 1536, avant la Dispute de Lausanne et l'édit de Réformation qui fut ensuite promulgué ${ }^{47}$, Sébastien Naegueli désigné comme gouverneur du château por les Messieurs de Berne ${ }^{\text {to }}$ fit procéder à un inventaire détaillé des biens du monastère et à l'interrogatoire des cinq religieuses. Il remit un double de l'inventaire aux Messieurs de Lausanne. Le Conseil fit procéder à un second inventaire le 6 novembre, après la soumission de Lausanne à Berne. Quoique le monastère fût supprimé par le fait même, les religieuses demeurèrent à Bellevaux jusqu'au 13 décembre 1537 . À cette date le Conseil leur ordonna de s'installer en ville dans la demeure confisquée du chanoine Jacques de Montfalcon. Chacune d'elles recevait une pension dont on nous donne le détail. Il ne restait plus à la charge de la ville, en 1548, que Françoise de Chissy entrée en religion en 1510. Tout ceci est correct. La légalité n'a rien à y redire. Mais s'agit-il bien de légalité ici? Que faut-il penser de cette correction et de la ponctualité avec laquelle les intègres fonctionnaires de Lausanne versaient à cette moniale une pension à vie devant cette autre chose à laquelle nul ne fait allusion: le viol des consciences? $\mathrm{Si}$ ces moniales n'avaient pas été priées de quitter leur petit monastère, l'une d'elles, Hélène Aigroz, ne se serait sans doute pas mariée, devenant par le fait même parjure aux voeux sacrés qu'elle avait jadis prononcés.

Les moines de Montheron ne partiront qu'en 1539, trois ans après la suppression de l'abbaye. Nous retrouverons ce même souci de correction au

47 Ci-dessus, $\mathrm{p}$.

40 Nous citons d'après Ernest Chavannes, Notice sur l'abbaye de Bellevaux, près Lausanne, "Mémoires et Documents publiés par la Société d'Histoire de la Suisse romande», XXXIV (1879), pp. 15-16. Lausanne. 
XIX ' siècle, quand les autorités de certains Cantons, après avoir chassé les moines, se feront scrupule d'expulser les religieuses. Ici, comme en Espagne et au Portugal, il leur suffit d'appliquer la loi qui interdit tout recrutement pour que les monastères périssent de mort lente. La légalité est respectée, mais la sentence est plus atroce que la dissolution pure et simple.

Une Congrégation cistercieme fut constituée sous sa forme définitive en 1618 , à la suite de tractations qui avient débuté en 1595. Elle prit le titre de Congrégation de Haute-Allemagne (Congregatio Cist. Superioris Germaniae) ${ }^{49}$. Cette Congrégation devint très prospère et dut être divisée en quatre Provinces dont celle d'Alsace-Brisgau et Suisse dans laquelle entrèrent, parmi plusieurs autres, les monastères suisses qui nous intéresent: Lüztel (Lucelle), Huterive (Altenryf), Sant Urban et Wettingen. Les monastères d'Allemagne furent sécularisés en 1803. Lucelle avait disparu en 1790. Il ne resta que les trois abbayes de Suisse qui formèrent en 1806 la Congrégation HelvétiqueCistercienne (Congregatio Helveto-Cisterciensis). Celle-ci disparut en 1848 avec la dissolution des derniers monastères de moines, Hauterive et Sant Urban.

Wettingen (Argovie) fut sécularisé le 13 janvier 1841 à la suite de l'affaire des Couvents d'Argovie ". L'abbé Léopold Höchle et quelques moines se réfugièrent le $1^{\text {" }}$ mars 1841 au château de Buonas, sur le lac de Zug (Schloss Buonas am Zugersee). Le 22 mai 1847, une partie de la communauté monastique se regroupait dans l'ancien couvent de franciscains de Werthenstein d'où ils furent expulsés six mois plus tard. Devant l'impossibilité de restaurer Wettingen, Dom Leopold Höchle acheta une ancienne abbaye bénédictine, Mehrerau, fondée en 1097 et supprimée en 1806. La vie monastique y reprit le 8 octobre 1854 ". Il fut décidé que Mehrerau serait considéré comme un prieuré de Wettingen dont le siège abbatial serait transféré dans la nouvelle fondation. Le «monastère consistorial et abbaye nullius» de Wettingen-Mebrerau qui comptait 50 moines en 1963 est le chef d'une Congrégation comprenant sept monastères et deux prieurés de moines et sept abbayes de moniales.

Les trois monastères de cisterciennes de Thurgovie avaient été supprimés

49 En allemand: Oberdeutsche Kongregation. Cf., C. BoCK, Les codifications du Droit cistercien, Westmalle (Belgique), 1950, p. 77; Gregor Mưller, Vom Cistercienser Orden, "Cistercienser-Chronik», 38 (1926), p. 291; D. WILLI, Die Oberdeut.sche und Schweizerische Zistercienser-Kongregation, Bregenz, 1879; SÉJALON, Nomasticon cisterciense, Solesmes, 1892, pp. 569-575. On doit ajouter un article publié dans la "Cistercienser-Chronik» (1936), sous le titre: Salem unter Abt Thomas I. Vurm und die Griindung der oberdeutschen Cist.Kongregation, en particulier les pages 230-239, 261-270, 294-306, 328-337.

so $\mathrm{Ci}$-dessus, $\mathrm{p}$.

"Voir à la table des monastères la localisation de Mehrerau et de MariasternGwiggen. 
par le décret du 27 juin 1848. Les religieuses de Kalchrain se retirèrent à Paradies, près de Schaffhouse. Après avoir en vain tenté de reprendre la vie régulière en Suisse, elles s'installèrent dans le château de Gwiggen, au nord de Bregenz, dans le Vorarlberg autrichien, le 30 octobre 1856, et y fondèrent le monastère de Mariastern-Gwiggen. Les cisterciennes de Feldbach se retirèrent d'abord à Tänikon, autre abbaye dissoute par le décret du 27 juin, mais que les religieuses continuèrent d'habiter jusqu'en 1853 . À cette date on leur signifia d'avoir à vider les lieux. Elles se réfugièrent alors, le 23 août de cette même année, à Mammern, près de Steckborn, qu'elles quittèrent pour rejoindre, en juillet 1864, l'abbaye de Mariastern-Gwiggen. Quant aux religieuses de Tänikon, c'est dans la ville de Frauenfeld qu'elles cherchèrent un asile en 1853, dans un couvent de capucins supprimé en 1848. Le 27 septembre 1869, elles rejoignirent les moniales de Kalchrain et de Feldbach à Mariastern-Gwiggen.

Suivons encore les cisterciennes de Rathausen, près de Lucerne. Chassées de leur monastère le 13 avril 1848, elles demandèrent asile aux moniales d'Eschenbach, dans le même Canton, qui avaient été épargnées. Elles y demeurèrent jusqu'en 1855, année où elles s'établirent dans la ville de Schwyz. En 1876, elles fondèrent le monastère de Saint-Joseph de Vézelise, dans la Meurthe-et-Moselle. Elles furent expulsées de France en 1901. Avec ténacité elles se mirent en quête d'un autre asile et, en 1902, elles s'établirent à Thyrnau, localité bavaroise située à 10 kilomètres de Passau. Le vieil esprit de l'héroïque Cîteaux inspirait ces moniales qui ne craignirent pas de braver les souffrances de l'exil pour demeurer fidèles à la Règle qu'elles avient vouée.

\section{Les Bernardines}

La Suisse abrite encore deux monastères de cisterciennes suivant une observance différente de celle que nous avons étudiée jusqu'ici. Fondée par la Mère Louise de Ballon qui avait subi l'influence de saint François de Sales, la Congrégation des Religieuses Bernardines fut approuvée par Urbain VIII le 24 juillet 1628. Un groupe de moniales fonda une maison à Saint-Maurice-enValais en 1629. Elles se transportèrent en 1634 à Monthey, un peu au nord. Puis, en 1647, à Collombey. Demeuré l'unique monastère de la Congrégation à partir de 1797, Saint-Joseph de Collombey fut supprimé en 1812 et réoccupé en 1814. Un groupe de moniales sorti de Collombey a fondé le monastère de Géronde le 2 mai 1935.

\section{D. ÉVOLUTION DES MONASTERES DE 1131 A 1966}

Nota.- Nous indiquons dans ce tableau les suppressions des monastères en en 
indiquant les raisons. Pour simplifier, nous les groupons sous deux chefs:

Religion: Réforme protestante; influence des doctrines de Zwingle.

Politique: Conséquences religieuses des idéologies politiques, celles-ci donnant origine à des lois anticléricales.

- Steinen, 1404.

Abandonné par les religieuses

- Selnau, 1525.

$$
\text { Religion (Zwingle) }
$$

- Kappel, 1527.

Religion (Zwingle, OEcolampe)

- Frienisberg; Fraubrunnen; Tetligen, 1528.

- Engenthal, 1534.

Religion (Berne: Guillaume Farel et Pierre Viret)

- Bellerive; Bellevaux; Bonmont; Montheron; Hautcrêt: 1536.

Politique (Révolution française)

- Lucelle; Kleinlützel: 1790.

Politique (Suppression des monastères allemands)

- Olsberg: 1805.

Politique (Affaire des Couvents d'Argovie)

- Wettingen: 1841.

Religion et politique (Guerre du Sonderbund) 1848.

- Sant Urban; Rathaussen; Kalchrain; Tänikon; Feldback; Hauterive:

- Gnadenthal: 1876.

$$
\text { Supprimé par l'Ordre }
$$

Abbayes existant en 1966

Moines: Hauterive.

Moniales: Fille-Dieu; Frauenthal; Magdenau; La Maigrauge; MariazellWurmsbach; Eschenback.

\section{E. LES TRAPPISTES EN SUISSE}

Le bref séjour des Trappistes en Suisse pendant la Révolution française et l'Empire a eu des répercussions considérables sur le développement ultérieur de l'Ordre de Cîteaux. Ce séjour et les événements qui le suivirent ont profondément marqué les moines exilés et tous ceux qui se réfugièrent auprès d'eux. Il est à l'origine de la division moderne en deux Observances: les cisterciens de la Stricte observance étant les successeurs des Trappistes et constituant aujourd'- 
hui un Ordre monastique distinct, au moins au regard du Droit ecclésiatique. Tous les moines de l'âge hérö̈que de la Valsainte, même ceux qui, à la suite de l'abbé de Darfeld Dom Eugène de Laprade, ont abandonné assez tôt les Règlements de Dom de Lestrange, ont subi l'empreinte de la forte personnalité du fondateur du refuge en Suisse qui mit à profit les quelques années paisibles qu'il vécut dans ce monastère pour organiser selon ses propres conceptions une observance monastique qui s'imposa ensuite grâce aux monastères qu'il restaura en France. Les historiens de la Trappe, principalement soucieux de mettre en relief le rôle providentiel de Lestrange considéré comme le «sauveur de Cîteaux» se préoccupent peu de donner au lecteur une chronologie précise et logique. Dans ce qui n'est trop souvent qu'un panégyrique, on passe sous silence l'existence, éphémère sans doute, mais néanmoins réelle, d'autres refuges que la Valsainte. Enfin on ignore absolument ce fait d'une grande importance: la Trappe, après le séjour en Suisse, n'était plus la Trappe de Monsieur de Rancé. Nous ne pouvons nous étendre ici sur ce sujet qui déborde les limites de notre étude, mais nous ne pouvons l'esquiver complètement.

Ce qu'on appelle $L a$ Trappe est une réforme d'un genre très particulier de l'Ordre de Cîteaux. Son promoteur, Arnand Jean Le Bouthillier de Rancé, naquit le 9 janvier 1626 à Paris ${ }^{\prime 2}$. A l'âge de douze ans il était pourvu de plusieurs bénéfices qui lui assuraient une existence confortable au détriment des moines soumis à la commende. Parmi ces monastères se trouvait l'abbaye de La Trappe ". Après une jeunesse mondaine, le jeune et brillant abbé de cour décida de se débarrasser de tous ses bénéfices et de réformer l'abbaye de la Trappe, le seul qu'il conservait. «Le 13 juillet 1663, il entrait au noviciat de Perseigne ${ }^{54}$ de l'Etroite Observance pour en être l'espérance, le soutien et le conservateur, ainsi que l'honneur».

L'Ordre de Cîteaux était alors divisé, en France, en deux Observances soumises toutefois au même chef. L'une, dite la Commune Observance, se prévalait des dispenses accordées par les Souverains Pontifes et qui adoucissaient les rigueurs de la règle cistercienne. L'autre, appelée Étroite Observance, reprenait la règle primitive dans toute la mesure du possible. L'un des points

'2 Il existe quelques vies de Rancé, à l'image de ce personnage discuté. Nous suivons un manuscrit provenant de l'abbaye de la Valsainte ou de celle de Darfeld conservé dans les archives de Port-du-Salut. Les quelques citations entre parenthèses données sans référence sont empruntées à ce cahier inédit.

3 Département de l'Orne, arr. de Mortagne-au-Perche, ct. de Bazoches-sur-Hoëne, $\mathrm{cm}$. de Soligny-la-Trappe. Monastère fondé en 1122, puis incorporé à la Congrégation de Savigny. Il devint cistercien en 1147 avec toutes les maisons de cette Congrégation et passa dans la filiation de Clairvaux.

${ }^{44}$ Sarthe, arr. Mamers, ct. La Fresnaye-sur-Chédouet, cm. Neufchâtel-en-Saosnois. Monastère fondé en 1145. Filiation de Cîteaux. 
qui divisaient ces deux courants monastiques était l'abstinence de nourriture carnée. Les moines de la Commune Observance, appelés non-abstinents, usaient de viande à certains jours pendant une partie de l'année. Les autres, ou abstinents, étaient obstinément végétariens. L'état des espirits était tel que ce détail fut à l'origine d'une Guerre des Observances qui constitue l'une des pages les plus pénibles et les moins édifiantes de l'histoire cistercienne.

Dom de Rancé devenu abbé régulier de la Trappe le 13 juillet 1664 prit résolument parti pour l'Étroite Observance. Il supprima dans son monastère tout ce qui, en matière d'alimentation, lui semblait contraire aux usages de Cîteaux et rétablit le travail manuel ". Le cloître "devra être une prison qui fait des coupables aussi bien de ceux qui ont conservé l'innocence que de ceux qui l'ont perdue, car les moines ne sont que des troupes de criminels et des pénitents publics... Plus de poisson, ni de beurre, ni d'oeufs dans la pitance de ces pénitents publics. Plus de paillasse pour se reposer la nuit. Les moines ne sortiront jamais du couvent. Ils y observeront un silence perpétuel» ${ }^{66}$. Jamais saint Bernard ni les fondateurs de Cîteaux n'avient tenu un pareil langage, et surtout ils n'avaient jamais envisagé la vie monastique sous cet aspect résolument pénitentiel.

Rancé composa des Règlements calqués sur les Us de Cîteaux ". La Règle sage et discrète de saint Benoît s'estompait un peu devant une règlementation caporalisée qui ne laissait au moine pratiquement aucune initiative tout au long de sa journée. Malgré ces rigueurs les postulants affluèrent et l'abbé de la Trappe se trouva vite à la tête d'une nombreuse communauté. Devenu le porte-parole de l'Étroite Observance, Rancé protesta au Chapitre général de 1667 contre la Constitution In Suprema d'Alexandre XII dans laquelle le pape préconisait une observance moyenne qui pourrait être acceptée sans difficultés par les deux parties. Convaincu d'être l'authentique représentant du monachisme traditionnel, Rancé ne l'entendait pas ainsi. N'ayant pu faire triompher sa thèse, il se retira dans son monastère, farouchement décidé à mener à bien sa réforme sans plus se soucier de ce que l'on ferait ailleurs. $\grave{A}$ partir de ce moment, la Trappe mena une existence en marge de Cîteaux.

Dom Pierre Olivier, dixième successeur de Monsieur de Rancé sur le siège abbatial de la Trappe, mourut au début de 1790. Le monastère était gouverné

" R.T. (le chanoine Trilhe, ancien moine cistercien) a démontré dans ses Remarques sur l'abstinence établie par l'abbé de Rancé parues dans la "Revue Mabillon» (avril-juin 1937) que Rancé a considérablement exagéré dans le sens du rigorisme. Mais l'abbé de Lestrange, dans les Règlements de la Valsainte, a réussi à accentuer encore ces outrances.

s6 Daniel-Rops, Saint Bernard et ses fils, Paris-Tours, Mame éd., 1961, p. 139. Les passages en italique sont des citations de Rancé.

"Les Règlemens de l'Abbaye de Nostre-Dame de la Trappe en forme de Constitutions, Paris, 1698. 
par le prieur, Dom Gervais Brunel. Les graves événements qui agitaient la France laissaient les Trappistes indifférents. Vivant loin du monde, n'inquiétant personne, menant une existence austère, travaillant avec autant d'acharnement que les humbles paysans, leurs voisins, faisant d'abondantes aumônes, ils pensaient, dans leur simplicité, que ces raisons suffisaient pour les préserver.

Un moine ne partageait pas cet optimiste. Né dans l'Ardèche en 1754, Dom Augustin de Lestrange était maître des novices. Un témoin oculaire, le Trappiste de la Valsainte, s'exprime sans ambages dans son manuscrit: «Il ne partagea pas la prétendue résignation de ceux qui disoient autour de lui que sous le prétexte de la soumission aux ordres de Dieu, ils devoient subir la suppression comme un châtiment du ciel. Ce raisonnement étoit absurde. Dom Augustin, au contraire, jugea qu'il falloit chercher à sauver son Ordre par tous les moyens possibles».

Le prieur effrayé et doutant de l'avenir ne savait quelle décision prendre. Tantôt encourageant Lestrange, tantôt le brimant, allant même jusqu'à subtiliser sa correspondance avec les supérieurs de l'Ordre, il le laissa cependant tenter une expérience. Le Sénat de Fribourg était disposé à accueillir 24 moines, pas un de plus, dans l'ancienne chartreuse de la Valsainte. Ce monastère avait été fondé en 1295 par Girard de Corbières et sécularisé en 1777. Dom de Lestrange réussit à mener à bien les négociations. Il s'était muni de l'autorisation de Dom de Raucourt, abbé de Clairvaux et Père-Immédiat de la Trappe, et de celle de Dom François Trouvé, abbé de Cîteaux. Entre-temps la Trappe avait été supprimée le 4 décembre 1790 par l'Assemblée Constituante, ce qui avait enfin ouvert les yeux aux moines.

Le I " juin 1791, 24 Trappistes -16 religieux de choeur et 8 converss'installaient à la Valsainte. Au mois du juillet suivant Dom de Lestrange et ses moines décidèrent de renforcer les austérités de l'observance de Rancé. Cette réforme est connue dans l'histoire monastique sous le nom de Réforme de la Valsainte. Le très long titre des Règlements édités en $1794^{\circ 8}$ indique en quel sens elle se fit: «Règlemens de la Maison-Dieu de N. -D. de la Trappe, par $\mathbf{M}^{r}$ de Rancé... mis en nouvel ordre et augmentés des Usages particuliers de la Maison-Dieu de la Val-Sainte de N. -D. de la Trappe... choisis et tirés par les premiers religieux de ce monastère de tout ce qu'il y a de plus clair dans la Règle de St Benoît, de plus pur dans les Us \& Constitutions de Cîteaux, de plus vénérable dans les Rituels de l'Ordre, \& enfin de plus réfléchi dans leurs propres délibérations...». C'est ce dernier point, que nous avons souligné, qui fit gauchir la réforme en l'éloignant de l'authentique interprétation de la règle cistercienne. «La Trappe suisse, écrit encore le moine de la Valsainte, reprit la pratique

${ }^{\text {s }}$ En 2 volumes, chez Béat-Louis Piller, Imprimeur de LL.EE., Fribourg. 
littérale de la Règle de Cîteaux, selon saint Benoît, saint Étienne et saint Bernard, que la difficulté des temps avait empêché Monsieur l'Abbé de Rancé, premier réformateur de la Trappe, de reprendre comme il l'aurait désiré». C'est admettre que la réforme de Rancé avait été incomplète, au moins d'après la conception que s'en faisait Dom de Lestrange. Le séjour en Suisse marque ainsi une étape importante dans l'évolution de l'ancienne Étroite Observance. En fait, quoi qu'en aient écrit les historiens de la Trappe au XIX' siècle, celle-ci avait entièrement disparu avec la supression des monastères en 1790. La Trappe de Rancé que Lestrange voulait perfectionner et adapter s'en écartait sur un certain nombre de points et lui était presque étrangère. Quand se déchaîna la tourmente révolutionnaire, les deux Observances rivales en France étaient déjà ce qu'on est convenu d'appeler des Trappistes. Ils le signifièrent en donnant à leur refuge le titre de N. -D. de la Trappe de la Valsainte, comme plus tard Darfeld sera la Trappe de N. - D. de l'Eternité. C'est à partir de ce moment que ce nom de Trappe fut appliqué à tous les monastères issus de la maison de Suisse. Plusieurs des coutumes dont on a fait endosser la paternité à Rancé ne remontent qu'à Lestrange et à la Valsainte. Ses Règlements ne furent jamais approuvés par Rome, mais ils n'en façonnèrent pas moins la mentalité des moins qui les observaient, et il faudra attendre le milieu du XX siècle pour que les Trappistes les abandonnent et deviennent des Cisterciens.

Les postulants affluaient à la Valsainte. Ce n'étaient pas uniquement des Trappistes, mais aussi des Cisterciens des deux Observances françaises, des Bénédictins, des prêtres séculiers. Le Sénat de Fribourg maintenait à 24 le nombre de religieux qui devaient séjourner au monastère. Cet afflux risquait de l'indisposer. Dom de Lestrange avait aussi regroupé des religieuses pour lesquelles il avait fondé, le 14 septembre 1796, le monastère de Notre-Dame de la Trappe de la Sainte-Volonté-de-Dieu à Sembrancher, dans le Valais, là où résidait déjà un groupe de moines.

Le sous-prieur de la Trappe, Dom Gérard Bollangié, avait aussi cherché un refuge en Suisse. Il s'installa avec quelques moines à Widlisbach, dans le Canton de Soleure. Ce petit monastère créé en 1791 sous le vocable de Notre-Dame de la Miséricorde dura jusqu'à la mort de Dom Gérard en 1795. Il fonda un deuxième établissement, en 1793, à Saint-Pierre-de-Clages (Valais), dans un ancien prieuré bénédictin. L'entente ne règnait pas entre Dom Gérard et Dom de Lestrange. Tandis que l'un exagérait les rigueurs de l'observance rancéenne, l'autre cherchait à la tempérer en tombant dans l'excès opposé. Dom Gérard était en relations épistolaires avec plusieurs abbés cisterciens, dont ceux de Wettingen et de Salem ". Quand il mourut, ses moines qui ne

s9 La «Cistercienser-Chronik» (1929) a publié toute une correspondance en allemand et en latin concernant D. Gérard Bollangié et ses fondations. Voir pp. 4-14, 38-47, 75-78, 
suivaient pas les Règlements de la Valsainte se réfugièrent dans des abbayes autrichiennes.

Pressé par la nécessité, Dom de Lestrange se vit contraint de multiplier les fondations. Le 28 août 1793 quelques moines quittèrent la Valsainte avec mission de s'installer au Canada. Ne pouvant s'embarquer à cause du blocus continental, ils s'établirent à environ 16 kilomètres à l'est d'Anvers dans une ferme curieusement nommée Nooit Rust (Jamais de repos), près de la petite ville de Westmalle, le 6 juin 1794. Le 17 juillet suivant, ils durent s'enfuir devant les troupes de Dumouriez qui marchaient sur la Hollande. Après avoir séjourné pendant une année dans le monastère cistercien de Marienfeld, près de Warendorf, en Westphalie, ils prirent possession, le 16 octobre 1795, d'un petit domaine près du village de Darfeld un peu au nord-ouest de Münster. $\mathrm{Ce}$ nouveau monastère nommé $N$. $-D$. de la Trappe de l'Éternité fut à l'origine de trois abbayes françaises lors de la restauration en France ${ }^{60}$.

Deux moines partis en 1793 pour l'Espagne séjournè rent pendant un certain temps dans l'abbaye cistercienne de Poblet, en Catalogne. Ils occupèrent, le 4 javier 1796, la grange de Santa Susana, en Aragon, dépendant de l'abbaye catalane de l'Escarp. D'autres partirent le 22 avril 1794 pour le Nouveau Monde. Ils ne purent aller plus loin que l'Angleterre où ils fondèrent dans le Dorset, en 1796, l'abbaye de Lulworth qui repeupla en 1817 l'ancien monastère de Melleray.

Les armées françaises envahirent la Suisse au mois de février de 1798. Dom de Lestrange regroupa les moines et les religieuses por fuir en Allemagne. $\mathrm{Ce}$ fut l'origine d'un extraordinaire exode qui les mena jusqu'en Russie. Ce qu'on a nommé l'Odysée monastique s'acheva en juillet 1800 à Hambourg. Quelques religieuses partirent de là pour l'Angleterre où elles fondèrent en 1802 le monastère de Stapebill.

La Valsainte fut réoccupée le 2 juillet 1802. Les religieuses s'installèrent d'abord à Villavolard le 26 octobre. Elles y restèrent jusqu'en 1804 . À cette date, elles se transportèrent plus au nord à la Grande Riedera qu'elles quittèrent pour occuper tout à côte, les bâtiments de la Petite Riedera, le 18 novembre 1805. Sembrancher avait été vendu. C'est à Géronde, près de Sierre, que se regroupèrent quelques moines. D'autres allèrent en Italie, à la Cervara, près de Gênes.

Malgré l'hostilité de Napoleón pour les religieux en général, le gouvernement français manifestait de la sympathie pour les Trappistes. Ceux-ci purent

104-109, 140-148, 174-180, 208-209, 233-239, 274-278, 362-364; (1930), pp. 13, 77-82, 106-108.

"60 Voir le tableau «Rayonnement de la Valsainte». Ce sont les abbayes de Port-duSalut (1815), du Gard (1816) et d'Oelenberg (1824). 
former de petites communautés près de Paris. Un groupe de religieux et de religieuses de l'Ancien Régime qui avaient continué à observer sous la Terreur, dans la mesure du possible, les Règlements de la Trappe, vivaient à Sénart. Ils furent affiliés en 1805. Dom de Lestrange transféra les moines à Gros-Bois, et les moniales à Valenton. Il fonda en 1806 un petit monastère au Mont-Valérien, à l'ouest de Paris, et un autre à Rome, au Mont Soracte. À la demande de Napoleón lui-même, et au bénéfice des armées impériales, six Trappistes installèrent un hospice au Mont-Genèure, près de Briançon, mais en territoire italien. Westmalle avait été réoccupé par des moines de Darfeld depuis 1802. D'autre part, Dom de Lestrange avait envoyé des religieux aux États-Unis. Ceux-ci débarquèrent à Baltimore le 4 septembre 1803. Un monastère fut fondé en 1806 dans le Kentucky, à Casey-Creek, à environ 50 kilomètres de Louisville.

On demeure confondu devant tant d'activité et tant d'audace quand on mesure les difficultés que devait surmonter l'abbé de la Valsainte. Toutes ces fondations étaient des prieurés dont il se réservait le gouvernement. Ces moines et ces religieuses ainsi dispersés continuaient à observer fidèlement les Règlements rigoureux qu'il leur imposait.

Santa Susana fut soustraite à la jurisdiction de Dom de Lestrange, élevée au rang d'abbaye et affiliée à la Congrégation cistercienne d'Aragon, en conservant toutefois les Règlements de la Valsainte. La situation de Darfeld était critique en 1806. Lestrange y prenait les meilleurs sujets et confisquait ses ressources financières sans se soucier des difficultés qui en résultaient. Les moines excédés se plaignirent. L'évèque de Munster s'iterposa, et Darfeld fut séparé de la Valsainte le 21 juin 1808. Dom Eugène de Laprade, son abbé, dut abandonner un peu plus tard, sur l'ordre de Rome, les Règlements de Dom de Lestrange et reprendre ceux de Rancé.

Puis ce fut l'épreuve. L'Empereur fit arrêter, le 11 juin 1811, Dom de Lestrange qui se préparait à fuir en Amérique. Relâché, l'abbé put se procurer un passeport pour la Suisse par surprise et arriva à la Valsainte au début d'août. Condamné à mort par contumace, il dut s'enfuir aux États-Unis, mais il avait auparavant obligé le supérieur de la Cervara à rétracter publiquement, le 16 juillet, un serments de fidélité prête à la constitution française. Napoleón réagit brutalement en faisant incarcérer le moines de la Cervara et en signant, le 28 juillet 1811 , le décret de Saint-Cloud qui supprimait tous les établissements de Trappistes. La Valsainte fut dissoute en 1812. Les religieuses de la Riedera ne furent pas inquiétées. Après la chute de Napoléon en 1814, le Trappistes réoccupèrent les monastères, dont celui de la Valsainte.

Les moines avaient hâte de revenir en France où l'Ordre avait complèment disparu. La rapidité avec laquelle ils fondèrent des abbayes d'apprécier à sa juste valeur l'importance extraordinaire de la Trappe suisse de la Valsainte où s'étaient réfugiés 24 moines en 1791. 
Darfeld fonda l'abbaye de Port-du-Salut ${ }^{61}$ le 21 février 1815. L'ancienne abbaye cistercienne du Gard fut restaurée en 1816. La communauté fut transférée en 1836 à Sept-Fons ${ }^{63}$. Les derniers moines de Darfeld vinrent à OElenberg ${ }^{64}$ en 1824. L'abbaye de la Trappe, désormais connue sous le nom de la Grande-Trappe, accueillit, le 6 décembre 1815, des moines rentrés d'Amérique. Les quelques Trappistes revenus à la Valsainte en 1814 s'installèrent à Aiguebelle "s le 23 décembre 1815. D'autres Trappistes revenus d'Amérique fondèrent Bellefontaine ${ }^{\circ}$ le 4 mai 1816 . La vie régulière avait repris à Westmalle le 21 août 1814. Les moines de Lulworth furent contraints de quitter l'Angleterre et vinrent à Melleray ${ }^{67}$ le 7 août 1817. Un ancien novice de Gros-Bois fonda Bricquebec avec l'aide de l'abbaye de Port-du-Salut, en 1822.

Si la Valsainte, restaurée par les chartreux en 1863, n'est plus abbaye de Trappistes, les 80 monastères de moines cisterciens de la Stricte Observance qui existent aujourd'hui proviennent tous du modeste refuge installé en 1791 dans le Canton de Fribourg.

La plupart des 42 monastères de moniales de la Stricte Observance ${ }^{60}$ lui doivent aussi l'existence par l'intemédiaire des abbayes de Laval, fondée par Darfeld, des Gardes et de Maubec, peuplées par les religieuses de la Petite Riedera.

${ }^{61}$ Mayenne, arr. Laval, ct. Laval-est, cm. Entrammes. Dans un prieuré de Chanoines réguliers fondé en 1233 et sécularisé à la Révolution.

${ }^{62}$ Somme, arr. Amiens, ct. Picquigny, cm. Crouy. Fondé en 1137. Filiation de Clairvaux par Cherlieu.

${ }^{63}$ Allier, arr. Moulins; ct. Dompierre-sur-Besbre, cm. Diou. Fondé en 1132. Filiation de Clairvaux par Fontenay.

64 Haut-Rhin, arr. Mulhouse, ct. Wittenheim, cm. Reiningue.

6s Drôme, arr. Nyons, ct. Grignan, cm. Montjoyer. Fondé en 1137. Filiation de Morimond. On donne aussi la date du 27 janvier 1816, jour où arriva Dom Étienne, supérieur, pour la fondation du monastère.

${ }^{66}$ Maine-et-Loire, arr. Cholet, ct. Beaupréau, cm. Bégrolles-en-Mauges.

${ }^{67}$ Loire-Atlantique, arr. Châteaubriant, ct. Moisdon-la-Rivière, cm. La Meillerayede-Bretagne. Fondé en 1145. Filiation de Cîteaux par Pontron et Le Loroux.

${ }_{68}$ Manche, arr. Cherbourg, ct. et $\mathrm{cm}$. Bricquebec.

69 Mais non pas tous, car les abbayes de cisterciennes espagnoles d'Alloz, d'Arconada, d'Arévalo, d'Ávila (Santa Ana), de Benaguacil (anciennement La Zaydia de Valencia), de Carrizo et de Tulebras, ont été affiliées. La Fille-Dieu en Suisse, La Grâce-Dieu en France, Soleilmont en Belgique, sont aussi des affiliations. 
LES ABBAYES CISTERCIENNES DE SUISSE

421

\title{
F. TABLE GEÓGRAPHIQUE ET CHRONOLOGIQUE DES ABBAYES
}

Hom classons les notices par ordre alphabétique sous les rubriques suivantes:

\author{
1. Moines \\ 2. Moniales \\ 3. Saint Ordre de Citeaux \\ 4. Bernardines \\ 5. Trappistes
}

Les refuges et établissements provisoires sont indiqués à leur place dans l'ordre alphabétique. À la suite du nom du monastère et de l'indication de la filiation, vient la nom du Canton en français et en allemand, la langue officielle étant donnée la première. Les cartes utilisées pour la localisation sont les cartes au $50.000^{\circ}$ et au $100.000^{\circ}$ du Service topographique fédéral. On trouvera, après l'indication de l'échelle, le numéro de la feuille suivi, pour la carte au $50.000^{\circ}$, des chiffres du quadrillage kilométrique de la Suisse. Nous renvoyons ensuite à la carte Michelin au $200.000^{\circ}$, indiquée «Mi», suivie du numéro de la feuille et de celui du pli: Mi. $23 / 11=$ Michelin, feuille 23 , pli 11 . Il existe de nombreuses et excellentes cartes au $300.000^{\circ}$ au $400.000^{\circ}$ éditées par Kümmerly und Frey, à Berne, ainsi que' une carte d'ensemble au $300.000^{\circ}$ 'publiée par le Service topographique fédéral, et une carte au $400.000^{\circ}$ de Reise-und Verkehrsverlag (RV-Landkarten) de Stuttgart, sur lesquelles sont portés à peu prés tous les monastères. Nous avons choisi comme carte d'ensemble la Nouvelle carte de voyages et d'excursions de la Suisse (Neus Reise-und Tourenkarte der Schweiz) au 300.000 ' des éditions Zurlinden, de Zurich, qui est pourvue d'un corroyage auquel nous renvoyons de la manière suivante: Exc., suivie de la lettre et du chiffre. Là où il y a lieu de préciser en indiquant nos sources, nous donnons une brève bibliographie et nous citons au besoin la correspondance avec les archivistes des Cantons qui nous a été communiquée.

Nota: Les distances sont indiquées en ligne droite.

Nous indiquons ici les catalogues de monastères que nous avons utilisés pour l'etablissement de cette table. Nous y renvoyons une fois pour toutes:

- Sebastian BRUMER, Ein Cisterzienserbuch, Würzburg. Le chapitre: Die aufgehobenen Cisterzienserfrauenklöster in OEsterreich-Ungarn, Deutschland und der Schweiz (pp. 609-647) est de Berthold BBAYER.

- P. Marian GlONING, S.O. Cist., Verzeichnis der deutschen Cistercienzer Abteien und Priorate, dans «Studien und Mitteilungen zur Geschichte des Benediktinerordens un seiner Zweige» (1915), pp. 97-137. 
P. Blasius HUEMER, O.S.B., Verzeichnis de deutschen Cisterzienserinnenklöster, ibid., (1916), pp. 139-183.

J. Hartmann, Die Katbolischen Orden und Kongregationen der Schweiz, Immensee, 1936.

Fondation de la Congrégation cistercienne Helvéto-cistercienne. Extrait du préambule des Statuts de la Congrégation Helvéto-Germanique de 1894:

\begin{abstract}
«(1803) cum Salemitano monasterio et reliqua congregationis (per Superiorem Germaniam) monasteria ceciderunt et unica congregationis provincia, Alsato-Helveta supererat tria complectens monasteria Altam-Ripam, St.-Urbanum et Marisstellam (i.e. Wettingen)... Cura et laboribus Sebastiani Steinegger abbatis Marisstellani et dictae provinciae illo tempore Vicarius Generalis, Congregatio per Superiorem Germaniam continuata est, alio quidem nomine, sc. Cogregationis Helveto-Cisterciensis, sed isdem statutis et observantiis... Pius PP. VIl die 12. Dec. 1806 novam rerum dispositionem solemniter approbavit et Congregat. Superiori Generali ad triennum eligendo omnia iura et privilegia concessit, quibus antea Abbates Cistercii et postea Abbates Salemitani fruebantur».
\end{abstract}

Liste des monastères de la Province d'Alsace-Brisgau et Suisse avant la suppression de la Congrégation de Haute-Allemagne, d'après Gloning: «Zum Vikariat Elsass-Breisgau-Schweiz gehörten: Haute-Rive, Lützel, Neuburg, Pairis, Tennenbach, St. Urban in Luzern und Wettingen» (p.112).

Les divisions administratives placées après le nom du Canton sont prises dans le dictionnaire géographique de la Suisse, publié sous les auspices de la Société Neuchâteloise de Géographie, 6. ${ }^{\circ}$ vol., Neuchâtel, Attinger Frères éditeurs (1902-1810) et dans le Dictionnaire Historique et Biographique de la Suisse, 7 vol. et 1 supplément (1921-1934). Abréviations:

$$
\begin{aligned}
& \mathrm{ct}=\text { Canton } \\
& \mathrm{cm}=\text { Commune. } \\
& \mathrm{d}=\text { District }
\end{aligned}
$$

Nous renvoyons le lecteur aux deux ouvrages suivants dont la consultation est indispensable pour l'histoire et la geógraphie de la Confédération:

- William Martin, Histoire de la Suisse, Ge édition, Payot, Lausanne, 1966.

- F.W. Putzger, Atlas Historique, Se édition, Payot, Lausanne, 1965. Il s'agit d'un excellent atlas historique allemand adapté à la Suisse. Voir spécialement les cartes suivantes: carte II, page I: Les monastères en Suisse au moyen âge; page II: Les villes et les grandes voies de communication au moyen âge; page III:La Confédération et les Habsbourg.- La Confédération vers 1385; page IV: La répartition des confessions vers 1530 et vers 1700; page VII La Confédération de 1536 à 1798; page 45: Ausbreitung d. Zisterzienserordens; page 64: Die Eidgenossenschaft 1536-1798; der Bauernkrieg 1525. 


\section{MONASTÈRES DE MOINES}

1. BONMONT, Bonus Mons, Bermont, Bernon. Fil. de Clairvaux

Canton de Vaud (Vaadt), d. Nyon, $\mathrm{cm}$. Chéserex

$1 / 50.000$ : feuille 260 , quadrillage kilométrique: $501 / 140$

1/100.000 : feuille 40. Mi. 23/11. Exc.: L-2 (pas indiqué sur cette carte).

46. '24'30" $\mathrm{N}-6 .^{\circ} 09^{\prime} 00^{\prime \prime} \mathrm{E}$.

Diocèse de Genève.

$7 \mathrm{~km}$ nord-nord-ouest de Nyon; $5 \mathrm{~km}$ nord de Divonne-les-Bains. Au pied de la Dôle (Grande-Côte-de-Bonmont).

Fondé en 1123 pour des bénédictins par Gauthier et Étienne de Divonne. Affilié le 7 juillet 1131. Rattaché directement à Clairvaux. Supprimé en 1536 (Berne). Le domaine du monastère forma d'abord un «gouvernement» distinct du baillage de Nyon. En 1711, devient baillage indépendant. Domaine vendu au XVIII siècle. Château construit à la même époque. Église de pur style cistercien (XII's.), aujourd'hui grange à fourrage.

2. FRIENISBERG, Veneris Mons, Aurora. Fil.: Lucelle - Belevaux - Morimond.

Canton de Berne, d. Aarberg, cm. Seedorf

1/50.000: 233, 592/208. 1/100.000': 31; Mi. 21/14; Exc. G-8.

$47 .^{\circ} 01^{\prime} 47^{\prime \prime} \mathrm{N}-7 .^{\circ} 19^{\prime} 55^{\prime \prime} \mathrm{E}$.

Dioc. de Constance, auj. Bâle et Lugano.

$14 \mathrm{~km}$ sud-sud-est de Biel; $22 \mathrm{~km}$ ouest de Burgdorf.

Fondé par Udalhard von Sogern. Occupé le 15 mai 1138 par des moines venus de Lucelle. Suprimé en 1528 (Zwingle).

3. HautCret, Alta Crista. Fil.:Cherlieu - Clairvaux.

Carton de Vaud (Vaadt), d. Oron, $\mathrm{cm}$. Les Tavernes

1/50.000 : 262, 552/156; 1/100.000': 41; Mi. 23/4; Exc. K-5.

$1 / 25.000$ : feuille 1244 .

46. ${ }^{\circ} 33^{\prime} 28^{\prime \prime} \mathrm{N}-6 .^{\circ} 49^{\prime} 05^{\prime \prime} \mathrm{E}$.

Dioc. de Lausanne.

Commune: Les Tavernes. Sur la rive gauche de la Broye. A $600 \mathrm{~m}$ au nord du hameau de Haut Crêt. $14 \mathrm{~km}$ est-nord-est de Lausanne; $17 \mathrm{~km}$ sud-sudouest de Romont. Dans le «Dézaley», au nord-est de la commune des Tavernes. Vers 1134: donation du terrain par Guy de Maligny, évêque de Lausanne, et le comte Amédée de Blonay. Fondation le 14 mars 1143 . Supprimé en 1536 (Berne). Les moines plantèrent un vignoble célèbre qui est aujourd'hui propriété de la ville de Lausanne. 
4. Hauterive (Altenryf) Alta Ripa. Fil.: Cherlieu - Clairvaux. Canton de Fribourg (Freiburg), d. Sarine, cm. Posieux. 1/50.000 : 252, 575/179; 1/100.000: 36; Mi. 23/5; Exc. J-7. 46. '45' $02^{\prime \prime} \mathrm{N}-7 .^{\circ} 07^{\prime} 10^{\prime \prime} \mathrm{E}$.

Dioc. de Lausanne. bourg.

Sur la rive gauche de la Sarine. $5 \mathrm{~km}$ sud-ouest/sud-sud-ouest de Fri-

Fondé le 25 février 1138 par Guillaume de Glâne qui s'y fait convers et y meurt le il février 1143. Appartient à la Congrégation de Haute-Allemagne (Oberdeutsche Kongregation. - Provinz Elsass-Breisgau-Schweiz) de 1595/ 1618 à 1803/1806, et fait ensuite partie de la Congrégation Helvétocistercienne, de 1806 à 1848 . Supprimé par les autorités cantonales en 1848. Devient école normale de Fribourg. Restauré en 1939. Filiation actuelle: Wettingen-Mehrerau - Salem - Lucelle - Bellevaux - Morimond.

5. Kapell, Capella, Capellen. Fil.: Hauterive - Cherlieu - Clairvaux. Canton de Zürich, d. Affoltern, $\mathrm{cm}$. Kappel

1/50.000 : 225, 682/231; 1/100.000: 32; Mi. 21/17; Exc. E-14. 47. '13'40" $\mathrm{N}-8$. $^{\circ} 31^{\prime} 30^{\prime \prime} \mathrm{E}$.

Dioc. de Constance, auj. de Chur (Coire).

$16 \mathrm{~km}$ au sud de Zürich, $25 \mathrm{~km}$ au nord-est de Luzern, $7 \mathrm{~km}$ au nord de Zug.

Fondé en 1185 par Konrad von Eschenbach, Abbé de Murbach, son frère Ulrich, Prieur de Luzern, et Walter von Schnabelburg. Peuplé le 29 juin de la même année par des moines d' Hauterive. Saccagé en 1413 (Eidgenossen). Sécularisé en 1527 (Zwingle). En 1531, bataille de Kappel où succomba Zwingle.

Aujourd'hui: orphelinat et hôpital.

6. KleiNlUTZEL, Lucella Minor, Petite Lucelle. Fil.: Lucelle - Bellevaux - Morimond.

Canton de Solothurn (Soleure), d. Thierstein, $\mathrm{cm}$. Klenliitzel

1/50.000 : 223, 598/253; 1/100.000: 31; Mi. 21/3; Exc. D-9.

47. ${ }^{\circ} 25^{\prime} 37^{\prime \prime} \mathrm{N}-7 .^{\circ} 25^{\prime} 13^{\prime \prime} \mathrm{E}$.

Dioc. de Bâle. Lützell.

$20 \mathrm{~km}$ sud-ouest de Bâle; $37 \mathrm{~km}$. sud de Mulhouse. Sur la rive droite de la

Prieuré refuge des cisterciens de Lucelle en 1505. Supprimé en 1790 (Révolution française).

7. LuCELle(GrosslutZel), Lucis Cella. Fil.: Bellevaux - Morimond. ct. Berne, d. Délémont, cm. Pleigne. 
En France. Dép. Haut Rhin, arr. Altkirch, ct. Ferrette, cm. Lucelle. 1/50.000 : 223, 585/252; 1/100.000: 31; Mi. 21/3; Exc. D-8. 47. ${ }^{\circ} 25^{\prime} 18^{\prime \prime} \mathrm{N}-7 .^{\circ} 15^{\prime} 30^{\prime \prime} \mathrm{E}$.

Dioc. de Bâle, auj. Strasbourg.

Note sur la nationalité de ce monastère. C'est par erreur que Mülinen, Helvetia Sacra, 1. Teil (Bern, 1858), p. 189, écrit: "Cistercienserabtei Lützel im ehemaligen Sundgau und jetzigen Kanton Bern, Bistums Basel ... am rechten Ufer der Lützel gelegen...». Le Sundgau ou Haute-Alsace (auj. HautRhin) n'a jamais appartenu au Canton de Berne. L'abbaye de Lucelle se trouve sur la rive droite de la Lucelle, rivière qui forme frontière à cet endroit, et non sur la rive gauche. À une certaine époque, la frontière passait par la cuisine du monastère et une pierre placée près de l'âtre matérialisait cette frontière. L'indication du diocèse de Bâle, sans autre précision, prête à équivoque. Il s'agit de l'ancien diocèse, et non pas du diocèse moderne tout entier en Suisse. La localité dite Lucelle appartient à la France et à la Suisse, mais l'abbaye a toujours été dans la partie française.

Fondé par Hugues, Amédée et Richard de Montfaucon et leur oncle Berthold, évêque de Bâle, le 25 mars 1124. Supprimé en 1790 (Révolution française) et abandonné définitivement par les moines en 1792. Les moines avaient dû se réfugier dans leur prieuré de Kleinlützel en 1505 (voir ce mot). Chassés par la guerre de Trente Ans, ils durent encore abandonner leur monastère de 1632 à 1657.

Celui-ci fut brûlé en 1699 et reconstruit en 1711 .

8. MONTHERON, Gratia Dei, Thela, Quentella. Fil.: BellevauxMorimond. Canton de Vaud (Vaadt), d. et $\mathrm{cm}$. de Lausanne.

1/50.000 : 251, 541/160; 1/100.000': 35; Mi. 33/3; Exc. K-5.

46. ${ }^{\circ} 35^{\prime} 30^{\prime \prime} \mathrm{N}-6 .^{\circ} 39^{\prime} 52^{\prime \prime} \mathrm{E}$.

Dioc. de Lausanne.

Entre Cugy et Froideville, à la lisière nord du Bois du Jorat, entre le bois d'Archens et le bois de Brenenté sur la route joignant Cheseaux à Froideville. Rive droite du Talent, au confluent du Talent et du ruisseau de Benenté. $8 \mathrm{~km}$ nord-nord-est de Lausanne; $6 \mathrm{~km}$ sud-sud-est d'Echallens.

Fondé par l'évêche Gérold de Faucigny en 1128. Peuplé le 24 mars 1135 par des moines de Bellevaux. Supprimé en 1536 (Berne). L'origine de ce monastère est obscure. Fondé sous le nom de Thela, près de Sainte-Catherine. Occupé en 1135 par Bellevaux sous le nom de Gratia Dei. Transféré ici en 1147 (Cf. Lexikon für Theologie und Kirche, VII, col. 306). Église restaurée en 1929/ 1931. L'abbaye est aujourd'hui une ferme.

Bibl.: Maxime REYMOND, L'Abbaye de Montheron, «Mémoires et docu- 
ments», publiés par la Société d'Histoire de la Suisse romande, seconde série, $\mathrm{X}$, Lausanne, 1918.

9. SANT URbAN, Sanctus Urbanus. Fil.: Lucelle - Bellevaux - Morimond.

Canton de Luzern (Lucerne), d. Willisan, $\mathrm{cm}$. Pfaffnau

1/50.000; 224, 630/631; 1/100.000; 32; Mi. 21/15; Exc. E-11. $47^{\circ} 14^{\prime} 00^{\prime \prime} \mathrm{N}-7^{\circ} 50^{\prime} 30^{\prime \prime} \mathrm{E}$.

Dioc. de Constance, auj. Bâle.

$15 \mathrm{~km}$ au sud d'Olten; $23 \mathrm{~km}$. à l'est de Solothurn.

Sur la rive droite de la Rot.

Fondé par Ulrich von Langenstein en 1194 à Kleinroth, dans le Canton de Berne, à $3 \mathrm{~km}$ au sud du site actuel de Sant Urban. Transféré ici en 1195 . Peuplé par des moines de Lucelle. Supprimé le 13 avril 1848 (Guerre du Sonderbund). Bâtiments conservés.

10. Wettingen, Maris Stella. Fil.: Salem-Lucelle - BellevauxMorimond Canton d'Aargau (Argovie), d. Baden, cm. Wettingen. 1/50.000; 215, 666/256; 1/100.1000; 27; Mi. 21/6; Exc. D-13 $47^{\circ} 27^{\prime} 23^{\prime \prime} \mathrm{N}-8^{\circ} 18^{\prime} 55^{\prime \prime} \mathrm{E}$.

Dioc. de Constance, auj. Bâle.

2,5 $\mathrm{km}$ au sud-sud-est de Baden. Au sud de la ville de Wettingen, Sur la rive droite, dans boucle formée par la Limmat, affluent de la rive droite de l'Aar.

Fondé en 1226 par le comte Hernri de Rapperswild qui y prit l'habit cistercien et y mourut en 1246. Placé dans la filiation de Salem en 1227. Supprimé le 13 janvier 1841 (Affaire des Couvents d'Argovie). Les moines se réfugient le $1^{\text {" }}$ mars 1841 au château de Buonas, sur le lac de Zug, au sud de Cham (feuille au $1 / 50.000^{\circ}$, n. $^{\circ} 235,68 / 221$ ), puis, le 22 mai 1847, dans un ancien couvent de franciscains à Werthenstein d'où ils furent expulsés six mois plus tard. Ils fondent alors l'abbaye de Mehrerau (voir ce mot), près de Bregenz, le 18 octobre 1854.

Le monastère, parfaitement entretenu par les autorités cantonales, est aujourd'hui école normale supérieure du Canton d'Argovie.

\section{MONIALES}

\section{BELLERIVE, Bella ripa.}

Canton de Genève (Genf), $\mathrm{cm}$. Collonges - Bellerive.

1/50.000; 270, 504/123; 1/100.000, 40; Mi. 23/12; Exc. M-2.

46. $15^{\prime} 15^{\prime \prime} \mathrm{N}-6^{\circ} 10^{\prime} 35^{\prime \prime} \mathrm{E}$.

Dioc. de Genève. 
6,5 km au nord-est de Genève. Sur la rive du Léman, à l'ouest de Collonge.

Fondé vers $1254 / 1256$.

Supprimé en 1535 (Berne).

Abbaye rasée en 1536.

12. BelleVAUX, Bellavarda, Vaux-Sainte-Marie, Vallis et Mariae prope Lausannam.

Canton de Vaud (Vaadt), d. et $\mathrm{cm}$. Lausanne.

1/50.000; 261, 538/154; 1/100.000; 40; Mi. 23/3; Exc. K-5.

46. 32' $02^{\prime \prime} \mathrm{N}-6^{\circ} 38^{\prime} 02^{\prime \prime} \mathrm{E}$.

Diocèse de Lausanne.

$2 \mathrm{~km}$ au nord de Lausanne, entre le Bois Mermet et le Bois de Sauvabelin. Près du ruisseau de la Louvre. Un peu à l'écart de la ferme de Bellevaux. Le monastère a entièrement disparu.

Nommé d'abord «Vaux-Sainte-Marie».

Fondé en 1267 par le chevalier Berthold Bevroz pour des religieuses d'une règle indéterminée, peut-être celle de Prémontré. Incorporé à Cîteaux en 1293. Supprimé en 1536 (Berne).

Bibl.: Ernest CHAVANNES, Notice sur l'abbaye de Bellevaux près Lausanne, «Mémoires et Documents» publiés par la Société d'Histoire de la Suisse romande, $1^{\text {ier }}$ série, XXXIV, Lausanne, 1879.

\section{EBERSECKEN, Pura vallis.}

Canton de Luzern (Lucerne), d. Willisau, $\mathrm{cm}$. Ebersecken.

1/50.000', 234, 637/226; 1/100.000', 32; Mi. 21/15; Exc. F-11.

47. $11^{\prime} 02^{\prime \prime} \mathrm{N}-7 .^{\circ} 55^{\prime} 55^{\prime \prime} \mathrm{E}$.

Dioc. de Constance, auj. Bâle.

$18 \mathrm{~km}$ au sud d'Olten; $31 \mathrm{~km}$ nord-ouest de Luzern; $24 \mathrm{~km}$ sud-sud-ouest d'Aarau.

Fondé en 1274 par Rudolf von der Balm et Jakob von Fischlbach.

Peuplé par Rathausen. Supprimé en 1588. Rattaché en 1594 à Rathausen et démoli en 1688.

\section{ENGENTHAL, Arcta vallis.}

Canton de Basel-land (Bâle-Campagne), d. Arlesheim, cim. Muttenz.

1/50.000', 213, 617/262; 1/100.000', 25; Mi. 21/4; Exc. C-10.

$47 .^{\circ} 30^{\prime} 30^{\prime \prime} \mathrm{N}-7 .^{\circ} 40^{\prime} 05^{\prime \prime} \mathrm{E}$.

Dioc. de Bâle. $2,5 \mathrm{~km}$ sud-est de Muttenz; 3,8 km est de Münchenstein. Fondé en 1269 par le comte de Homburg. Détruit en 1525. Supprimé en 1534 (OEcolampe). 
Bibl.: EGILN, Die Ausgrabungen in ehemaligen Kloster Engenthal bei Muttenz, «Der Rauracher Quartalschrift der Gesellschaft Raurachischer Geschichtsfreunde», $2 / 3$ (1938).

15. ESCHENBACH, Sainte-Catherine, Ober-Eschenbach.

Canton de Luzern (Lucerne), d. Hochdorf, $\mathrm{cm}$. Eschenbach.

1/50.000; 235, 667/221; 1/100.000; 32; Mi. 21/16; Exc. F-13.

47. 08'02" N - 8..$^{\circ} 19^{\prime} 17^{\prime \prime} \mathrm{E}$.

Dioc. de Bâle.

$10 \mathrm{~km}$ au nord de Luzern.

Fondé le 24 février 1285 pour des Chanoineses de Saint-Augustin par Walter III et son frère Berthold II von Eschenbach. Incorporé à l'Ordre dans la Congrégation de Haute-Allemagne sous la paternité de Sant Urban, le 24 février 1588. Incorporation confirmée par Clément VIII, le 5 mai 1594. Erigé en abbaye par Dom Edme de la Croix, abbé de Cîteaux, le 17 avril 1595. Les moniales furent contraintes d'abandonner deux fois le monastère durant les guerres civiles. De 1848 à 1872, il leur fut interdit de recevoir des novices. Le monastère dépend aujorud'hui de Mehrerau.

Bibl.: Das Gotteshaus zu U.L. Frau und St. Katharina in Obereschenbach, 1285-1910, "Cistercienser-Chronik», 1910.

\section{FELDBACH, Rivus campi.}

Canton de Thurgau (Thurgovie), d. et $\mathrm{cm}$. de Steckborn. $1 / 50.000^{\circ}, 39^{\prime} 50^{\prime \prime} \mathrm{N}-8^{\circ} .58^{\prime} 30^{\prime \prime} \mathrm{E}$.

Dioc. Constance, auj. Bâle.

Directement à l'ouest de Steckborn, dans l'agglomération, sur la rive méridionale de l'Utersee. Route 13 de Schaffhausen à Konstanz.

Fondé en 1252 pour des Béguines par Walter et Ulrich von Klingen.

Devenu cistercien en 1256. Supprimé le 27 juin 1848 (Guerre du Sonderbund). Les moniales se réfugient le 4 octobre 1848 à Tänikon; le 23 août 1853 à Mammern; en juillet 1864 dans le Vorarlberg autrichien, près de Gwiggen. Avec les cisterciennes de Kalchrain et de Tänikon fondent le monastère de Mariastern-Gwiggen.

17. FILlE-DIEU, Filia Dei, Gottes-Tochter.

Canton de Fribourg (Freiburg), d. Glâne, com. Romont. $1 / 50.000^{\circ}, 252,561 / 172 ; 1 / 100.000^{\circ}$, 36; Mi. 23/4; Exc. S-6. 46. 42, 07' N - 6. $55^{\circ} 40^{\prime \prime} \mathrm{E}$.

Dioc. de Lausanne.

$1 \mathrm{~km}$ nord-est de Romont. Sur la rive gauche du Glaney, affluent de la Glâne, au confluent des deux rivières. À droite de la route de Romont à Fribourg, à la sortie des Chavannes. 
Fondé en 1268 par les trois soeurs Juliette, Pernette et Cécile de Villaz. Incorporé à la Stricte Observance (Trappistines) en 1905. Avait été d'abord soumis à l'abbaye d'Hautcrêt jusqu'à la suppression de ce monastère en 1536 , puis à Hauterive de 1593 à 1848.

18. FrAUbRUNNEN, Fons B.M.V., Fontana B.Virg.

Canton de Berne, d. et $\mathrm{cm}$. Fraubrunnen.

1/50.000, 233, 607/215; 1/100.000', 31; Mi. 21/14; Exc. F-9.

$47 .^{\circ} 05^{\prime} 08^{\prime \prime} \mathrm{N}-7 .^{\circ} 31^{\prime} 30^{\prime} \mathrm{E}$.

Dioc. de Constance, auj. Bâle.

$8 \mathrm{~km}$ au nord-ouest de Burgdorf; $13 \mathrm{~km}$ au sud de Soloturn. Sur la rive gauche de l'Urtenen.

Fondé en 1246 par le comte de Kyburg. Incendié en 1260 et 1375.

Supprimé en 1528 (Zwingle).

19. FRAUENFELD.

Canton de Thurgau (Thurgovie), d. et $\mathrm{cm}$. Frauenfeld.

1/50.000; 216, 710/269; 1/100.000; 28; Mi. 21/8; Exc. C-16.

47. 34'00" N - 8. $54^{\prime} 05^{\prime \prime} \mathrm{E}$.

Refuge des religieuses de Tänikon de 1853 à 1869.

20. FRAUENTHAL, Vallis Dominarum, Vallis Sanctae Mariae.

Canton de Zug, d. et $\mathrm{cm}$. Cham.

1/50.000', 235, 675/230; 1/100.000; 32; Mi. 21/17; Exc. E-14

$47 .^{\circ} 12^{\prime} 55^{\prime} \mathrm{N}-8^{\circ} 25^{\prime} 30^{\prime \prime} \mathrm{E}$.

Dioc. de Constance, auj. Bâle.

$4,5 \mathrm{~km}$ au nord-ouest de Cham; $19 \mathrm{~km}$ au sud-sud-ouest de Zürich. Sur la rive droite du Lorze.

Fondé en 1231 (ou vers 1240) par Ulrich von Schnabelburg et son épouse Agnes von Eschenbach. Pillé en 1352 par les gens de Schwiz, et en 1388 par les Autrichiens. Supprimé par la Réforme (Zwingle) en 1528, il fut restauré en 1552. Le monastère qui eut à souffrir des guerres civiles aux XVII ${ }^{\circ}$ et XVIII ${ }^{\circ}$ siècles, est aujourd'hui dans la filiation de Wettingen-Mehrerau.

\section{GNADENTHAL, Vallis Gratiarum.}

Canton Aargau (Argovie) d. Bremgarten, cm. Nesselnbach.

$1 / 50.000^{\circ}, 225,665 / 249 ; 1 / 100.000$; 32; 21/16; Exc. D-13.

$47 .^{\circ} 23^{\prime} 37^{\prime \prime} \mathrm{N}-8^{\circ} 10^{\prime \prime} \mathrm{E}$.

Dioc. de Constance, auj. Bâle.

$18 \mathrm{~km}$. à l'ouest de Zürich; $38 \mathrm{~km}$ au nord de Luzern. Sur la rive gauche de la . Reuss, entre Mellingen et Bremgarten. 
Fondé vers 1282 pour des Béguines. Les religieuses se disent cisterciennes en 1305 et 1313. En 1310 on trouve: «des ordens von Citel (sic)». Elles sont placées en 1318 dans la dépendance de l'abbé de Wettingen, et affiliées officiellement en 1394. Monastère supprimé en 1841 (Affaire des couvents d'Argovie) et restauré en 1843 comme prieuré. Définitivement supprimé en 1876. Est aujourd'hui un asile d'aliénés. Id. Steckborn, $\mathrm{cm}$. Hüttwilen.

\section{KalChrain, Cella B.M.V. ad Clivum Calcarium.}

Canton de Thurgau (Thurgovie), I.

$1 / 50.000^{\circ}, 216,709 / 274 ; 1 / 100.000$, 28; Mi. 21/8; Exc. C-16.

47. $36^{\prime} 45^{\prime \prime} \mathrm{N}-8^{\circ} 53^{\prime} 25^{\prime \prime} \mathrm{E}$.

Dioc. de Constance, auj. Bâle.

- Orthographie moderne: Chalcheren.

À $6 \mathrm{~km}$ au nord de Frauenfeld.

Fondé vers 1230/1238 pour des Béguines par Ulrich et Walter von Hohenklingen. Affilié le 19 mai 1328. Supprimé en 1529 (Zwingle), il fut restauré en 1562 par Feldbach. Définitivement supprimé le 27 juin 1848 (Guerre du Sonderbund). Les religieuses se retirent à Paradies et, le 30 octobre 1856, s'établissent à Mariastern-Gwiggen.

\section{MagdenaU, De Augia Virginum, Augi ancillarum.}

Canton: Sant Gallen (Saint-Gall) d. Untertoggenburg, cm. Degersheim. 1/50.000, 227, 731/251; 1/100.000', 33; Mi. 21/19; Exc. D-17. 47. 24' 12" N - 9. $10^{\prime} 15^{\prime \prime} \mathrm{E}$.

Dioc. de Constance, auj. de Saint-Gall.

$15 \mathrm{~km}$ à l'ouest de Sant Gallen; $2 \mathrm{~km}$ au sud-est de Flawil; $33 \mathrm{~km}$ est-sud-est de Winterhur.

Fondé le 3 avril 1244 par Rudolf Giel von Glattburg. Supprimé en 1529 (Zwingle), mais restauré en novembre 1532.

24. MaIraUge, (MAgeraU), Augia macra, Dürre Au.

Canton de Fribourg (Freiburg), d. Sarine, cm. Fribourg.

1/50.000', 242, 579/183; 1/100.000; 36; Mi. 23/5; Exc. H-7. $47 .^{\circ} 48^{\prime} 02^{\prime \prime} \mathrm{N}-7 .^{\circ} 09^{\prime} 30^{\prime \prime} \mathrm{E}$.

Dioc. de Lausanne.

À l'ouest de la ville de Fribourg, sur la rive droite de la Sarine.

Monastère de bénédictines fondé le 3 juillet 1255. Affilié le 31 juillet 1261 et placé sous la paternité d'Hauterive. Condammé à disparaître «par voie d'eretinction» (décret de 1848). Replacé en 1901 dans la jurisdiction de l'Ordre. Depuis 1950, dans la filiation de Wettingen-Mehrerau. 


\section{MAMMERN.}

Canton de Thurgau (Thrugovie), d. et $\mathrm{cm}$. Steckborn.

1/50.000; 206, 711/278; 1/100.000; 28; Mi. 21/9; Exc. B-16.

Dioc. de Constance, auj. Bâle.

5,5 k, ouest-sud-ouest de Steckborn. Sur l'Utersee, Route N. 13.

Refuge des religieuses de Fedbach de 1853 à 1864.

26. Mariazell-Wurmsbach, Cella Sanctae Mariae in Wurmsbach. Canton de Sant Gallen (Saint-Gall), d. Lac, cm. Jona.

$1 / 50.000$; 226, 708/231; 1/100.000; 33; Mi. 21/18; Exc. E-16.

47. $13^{\prime} 15^{\prime \prime} \mathrm{N}-8 .^{\circ} 51^{\prime} 55^{\prime \prime} \mathrm{E}$.

Dioc. de Constance, auj. Sant Gallen. Sur la rivenord, à l'extremité est du lac de Zürich. 3,5 km à l'est de Rapperswild.

En 1250, le comte Rodolf von Rapperswild fonde un couvent de cisterciennes à Oberbolligen (même carte, sur le lac, 3,5 km à l'est de Wurmsback. Il reprend le château et trois pièces de terre en 1259 parce que les moniales étaient passées à l'Ordre de Prémontré. (Ober) bollingen est de nouveau affilié à Cîteaux en 1263 à la demande des abbés de Lucelle, Frienisberg, St. Urban et Wettingen. Le monastère est uni en 1267 à celui de Mariazell, à Wurmsbach. Celui-ci avait été fondé en 1259 par Rodolf von Rapperswild pour les religieuses du couvent de Marienberg (auj. disparu) près de Kilchberg, qui adoptèrent la règle de Cîteaux et donnèrent au château de Wurmsbach le nom de Mariazell. L'incorporation de (Ober)bollingen eut lieu en 1261 et fut confirmée par Urbain IV en 1262. Mariazell-Wurmsbach eut à soufrir en 1656 au cours de la première guerre de Vilmergen.

Bibl.: S. BRUNNER, Ein Cisterzienserbuch, Würzburg, 1881, p. 738 et suiv.; Romain PITTET, L'abbaye cistercienne de la Fille-Dieu, Fribourg, 1934, p. 44; J. HARTMANN, Die Katholischen Orden, p. 287; «Cistercienser Chronik», Oct. 1967, p. 297.

27. OlSBERG, Gottesgarten, Hortus Dei.

Canton Aargau (Argovie), d. Rheinfelden, cm. Olsberg.

1/50.000; 214, 625/263; 1/100.000', 27; Mi. 21/5; Exc. C-10.

Dioc. de Bâle.

16 km à l'est de Bâle; 3,5 km au sud-sud-est de Rheinfelden. Le monastère est à 800 mètres à l'ouest de la petite localité d'Olsberg.

Fondé très probablement à Kleinroth (voir ce mot à la notice de Sant Urban) vers $1230 / 1235$. Il se transporte en 1236 ici, à Olsberg.

C'est le premier monastère de religieuses cisterciennes dans la Suisse actuelle. Supprimé le 29 mai 1805.

Bibl.: Lettre de Mr G. Boner, archiviste du Canton d'Argovie, Aarau, 22 
février 1962. Cette même lettre donnait des précisions que l'on trouvera à la notice de GNADENTHAL. Lettre du Dr. Werner Shcnyder, archiviste du Canton de Zürich, datée du 12 février 1962.

Georg BONER, Zur älteren Geschichte des Klosters Olsberg, "Von Jura zum Schwarzwald», 1961-1963.

\section{PARADISE.}

Canton de Thurgan (Thurgovie), d. Diessenhofen, $\mathrm{cm}$. Basadingen. $1 / 50.000^{\circ}, 206,693 / 282 ; 1 / 100.000$; 28; Mi. 21/8; Exc. B-15. 47. $41^{\prime} 10^{\prime \prime} \mathrm{N}-8$. $^{\circ} 40^{\prime} 412^{\prime \prime} \mathrm{E}$.

Dioc. Constance, auj. Bâle.

$3 \mathrm{~km}$ est-sud-est de Schaffhausen, sur la rive gauche du Rhin, route 13. Refuge des cisterciennes de Kalchrain de 1848 à 1856.

29. RATHAUSEN, De consilio domus.

Canton de Luzer (Lucerne), $\mathrm{cm}$. Ebikon

$1 / 50.000^{\circ}, 235,666 / 215$; 1/100.000', 32; Mi 21/16; Exc. F-13.

47. 04' 52' N - 8. '18' $52^{\prime} \mathrm{E}$.

Diocèse de Constance, auj. Bâle.

$3,5 \mathrm{~km}$ au nord de Luzern, sur la rive droite de la Reuss.

Fondé en 1245 à Ennethorw (environ $5 \mathrm{~km}$ au sud Luzern) pour des Béguines. Transféré en 1245 à Riedholz qui prit le nom de Rathausen en 1251 quand les Bégines furent affiliées à l'Ordre de Cîteaux. Monastère supprimé le 13 avril 1848 (Guerre du Sonderbund).

Les religieuses se réfugient à Eschenbach (1848-1855), puis dans la ville de Schwyz (1855-1876), ensuite à Vézelise (France). Expulsées de France, elles se sont établies en 1902 en Bavière, à Thyranau, localité située à $10 \mathrm{~km}$ de Passau.

30. SelnaU, Augia sancta, Selige Au.

Autrefois SELDENAU.

Canton de Zürich.

$1 / 50.000,225,683 / 247 ; 1 / 100.000$; 32; Mi., 21-7.

47. $22^{\prime} 11^{\prime \prime} \mathrm{N}-8^{\circ} 32^{\prime} 00^{\prime} \mathrm{E}$.

Dioc. de Constance, auj. Chur (Coire).

Ce monastère se trouvait devant les murs de la ville ancienne de Zürich, sur la rive droite de la Sihl. L'emplacement est aujourd'hui dans la ville de Zürich. Il ne reste absolument rien rien du monastère, mais le quartier a conservé le nom de "Selnau».

Fondé en 1256 par Adèle von Küssnacht pour des Chanoinesses Augustines. 
On admet communément qu'il fut affilié en 1264/1265. Cependant, on trouve une charte de 1259 portant la metion: «sorores ordinis sancti benedicti secundum constitutiones cisterciences» (Urkundenbuch von Stadt und Landschaft Zürich III, S. 154, Nr 1068). Monastère supprimé en 1525 (Zwingle). Rasé en 1757.

Bibl.: Lettre du Dr. Werner Schnyder, archiviste du Canton de Zurich, du 12 févr. 1962, donnant des précisions sur la localisation et la chronologie de cette abbaye.

31. STEINEN Auf der Au, Steina in Augia, Vallis de Swiz. Canton de Shcwyz, cm. Steinen.

1/50.000', 235, 689/211; 1/100.000', 32; Mi., 21/17 Exc. G-15. 47. $03^{\prime} 05^{\prime \prime}$ N. - 8. 36' $55^{\prime \prime} \mathrm{E}$.

Dioc. de Constance, auj. Chur (Coire).

$5 \mathrm{~km}$ au nord-nord-ouest de Schwyz.

Fondé avant 1262 , probablement vers 1253 , pour des Béguines. Affilié en 1267 à Cîteaux. Mal situé, il fut abandonné le 8 février 1404.

Réoccupé, il fut définitivement abandonné par les cisterciennes en 1504. Des dominicaines s'y établirent de 1574 à 1640 .

Bibl.: Renseignements communiqués par le Dr. Willy Keller, archiviste de Schwyz, par lettres du 8 mars et du 23 mars 1962.

F. BLASER, Die alte Kirchöre Steinen, Steinen, 1930; Josef SCHNELLER, Geschichtsfreund-Mitteilungen des Historischen Vereins der V Orte. Bd. 5 (1815), s. 1-67, Schwyz; Quellenwerk zur Entstebung der Schweizerischen Eidgenossenschaft, Abt. I, Urkunden, Band I.

\section{TÁnIKON, S. Anna, Maria Lilienthal.}

Canton de Thurgau (Thurgovie); d. Frauenfeld, cm. Aadorf.

1/50.000', 216, 711/260; 1/100.000, 28; Mi., 21/8; Exc. C-16.

$47^{\circ} 28^{\prime} 50^{\prime \prime} \mathrm{N}-8^{\circ} 54^{\prime} 30^{\prime \prime} \mathrm{E}$.

Dioc. de Constance, auj. Bâle.

$1,5 \mathrm{~km}$ sud-sud-est d'Aadorf; 8,5 km sud de Frauenfeld; sur la ligne de chemin-de-fer de Winterthur à St Gallen.

Fondé en 1249 par Eberhard von Bichelsee. Incorporé à l'Ordre en 1255/ 1256. Les religieuses passent à la Réforme le 2 octobre 1529, abandonnent le monastère et se retirent à Zürich. L'abbaye est restaurée en 1550 par des cisterciennes venues de Magdenau. Elle est supprimée le 27 juin 1848 (Guerre du Sonderbund). Les religieuses se réfugient dans la ville de Frauenfeld (1848-1869). Elles rejoignent ensuite le monastère de Mariastern-Gwiggen (voir ce mot) le 27 septembre 1869. 
33. THLILIEN

Auj. Detligen.

Canton de Berne, d. Aarberg, (m). Radelfingen.

1/50.(0)(0), 243, 587/206;1/10(0.0(0), 31; Mi., 21/13; Exc. (j-8.

470()$^{\circ} 10^{\prime \prime} \mathrm{N}-716^{\circ} 3()^{\prime \prime} \mathrm{E}$.

Dioc. de Constance, auj. Bâle.

$15 \mathrm{~km}$ au sud de Biel (Bienne); $27 \mathrm{~km}$ a l'ouest de Burgdorf; à $2 \mathrm{~km}$ de la rive droite de l'Aar.

Date de fondation inconnue. Le plas ancien document est date du l" janvier 1284. Supprime en 1528 (Berne).

Bibl: Identification de Tetligen avec Detligen: lettre du Dr. H. Specter, des archives de Berne, datée du 6 mars 1962. Chronologie: lettre du même du 15 mars 1962 .

\section{SAINT (ORDRE DE (IITEAUX}

Moines

\section{BIRNAU}

Allemagne (Bade-Wurtemberg)

1/50.()()( $)$ 2(07, 734/290; Exc., A-18; Mi., 21/10.

$\left.47 " 45^{\prime} 12^{\prime \prime} \mathrm{N}-9\right)^{\prime \prime} 13^{\prime} 25^{\prime \prime} \mathrm{E}$.

$5 \mathrm{~km}$ au sud-sud-est d'Überlingen; $2 \mathrm{~km}$ au nord-ouest d'Oberuhldingen.

Un peu à l'écart, à droite, de la route 31 joignant Lindau à Friedrischshafen et Überlingen, sur l'Überlingersee, branche nord du lac de Constance.

Fondé en 1384 par l'abbaye cistercienne de Salem. Lieu de pèlerinage.

Restauré en 1919 par Wettingen-Mehrerau. Prieuré conventuel dépendant de cette abbaye.

\section{Mehrerau; Wettingen-Mehrerau, Augia Maior, Bregenz "in} der Aw".

Autriche, Vorarlberg.

Fil.: Salem - Lucelle - Bellevaux - Morimond.

1/50.(0)(), 218, 772/264; 1/10(0.()(0), 28 bis; Exc., C-2().

$47^{\prime \prime} 3()^{\prime} 15^{\prime \prime} \mathrm{N}-9^{\prime \prime} 43^{\prime} 25^{\prime \prime} \mathrm{E}$.

Dioc. de Bregenz; abbaye "nullius".

Sur le lac de Constance; $2 \mathrm{~km}$ à l'ouest de Bregenz.

Kloster Mehrerau in Bregenz, Vorarlberg, Österreich.

Fondé en 1097 pour des bénédictins. Sécularisé en 1806.

18 octobre 1854: prieuré peuplé par les cisterciens expulsés de Wettingen (voir ce mot). Siège abbatial de Wettingen transféré ici. 
Supprime par le National-Soctalisme en 19)+1. Restaure a la fin de la Seconde (jucere Mondiale. Abbaye "nullius" le 4 avril 19)2. Chef de la Congrégation de Mehrerau (Congregation Augieniz). I. Abbe porte le titre d'Abbe de Weettingen et de Prieur de Mehrerau.

\section{Miniules}

35. MARIASTERN-GWIG(ikN, Mariat Stella.

Autriche, Vorarlberg.

$1 / 5(1.0(0), 218,775 / 271 ; 1 / 100.0(0), 28$ bis; Exc., (-20).

$\left.47^{\circ} 34^{\prime} 2\right)^{\prime \prime} \mathrm{N}-96^{\prime} 2()^{\prime \prime} \mathrm{E}$.

Dioc. de Bregenz.

$8 \mathrm{~km}$ au nord-nord-est de Bregenz; $7 \mathrm{~km}$ a l'est-nord-est de Lindau.

Un peu à l'écart, à droite de la route joignant Bregenz à Hohenweiler (frontière germano-autrichienne).

Fondé par les cisterciennes exilées de Kalchrain, Feldbach et Tänikon, monastieres supprimés le 27 juin 1848. Les religieuse's de Kalchrain s'y établirent le 30 octobre 1856; celles de Feldbach, en juillet 1864, et celles de Tänikon, le 27 septembre 1869). Date d'erection du monastère: 28 janvier 1861 . L'abbesse porte le titre d'Abbesse des monasteres unis de Kalchrain, Feldbach et Tänikon, et Prieure de Mariastern. Filiation de Wettingen-Mehrerau.

\section{BERNARDINES}

\section{COLLOMBEY, Columberium.}

Canton du Valais, d. Mort hey, cm. Collombey-Muraz.

1/50.(0)(0), 272, 562/124; 1/10(0.0()(), 41; Mi., 23/14; Exc., M-6.

$46 " 16^{\prime}\left(08^{\prime \prime} \mathrm{N}-6^{\prime \prime} 56^{\circ} 50^{\prime \prime} \mathrm{E}\right.$.

Dioc. de Sion (Sittich).

Route 37. A $2 \mathrm{~km}$ au nord de Monthey.

Bernardines transférées de Monthey ici, au château d'Arbignon, en 1647.

Monastère supprimé en 1812 et réoccupé en 1814.

\section{MONTHEY.}

Canton du Valais, d. et cm. de Monthey.

$1 / 5() .(0)(0), 272,562 / 122 ; 1 / 10(0.0()() ; 41 ; \mathrm{Mi}, 23 / 14 ;$ Exc. N-6.

$\left.\left.46^{\prime \prime} 13^{\prime}()()^{\prime \prime} \mathrm{N}-7^{\prime \prime}(0)\right)^{\prime 3} 3\right)^{\prime \prime} \mathrm{E}$.

Dioc. de Sion (Sittich).

Route 37.

Occupé en 16.34 par les religieuses venues de Saint-Maurice.

Transféré à Collombey en 1647. 
38. Saint-MaL:RICE-en-VALAIS.

Canton du Valais, d. et cm. St. Maurice.

1/50.0(0), 272; 566/118;1/100.(0)(0), 41; Mi., 23/14; Exc. N-6.

$\left.\left.4613^{\circ}(0)\right)^{\prime \prime} \mathrm{N}-7^{\prime}(0)\right)^{\circ} 30^{\prime \prime} \mathrm{E}$.

Route 37.

Fondé en 1629. Transféré à Monthey en 1634.

39. GERONDE:

Canton du Valais, d. et cm. Sierre.

1/50.0()(\%, 273, 6()8/126;1/10().(0)(); 41; Mi., 23/16; Exc. M-9.

$4617^{\prime}\left(08^{\prime \prime} \mathrm{N}-7^{\prime \prime 3} 33^{\prime 2} 20^{\prime \prime} \mathrm{E}\right.$.

Dioc. Sion (Sittich).

Rive droite du Rhône, entre le fleuve et la ville de Sierre. Sur la route joignant Sierre à Chippis.

Peuplé par des Bernardines venues de Collombey le 2 mai 1935. Érigé canoniquement le 8 mai 1936.

\section{TRAPPISTES}

40. GERONDE.

Pour la localisation voir notice n." 39.

Ancien prieuré de chanoines réguliers fondé en 1233. Successivement occupé par des chartreux (1331-1354), des carmes (1425-1644), des jésuites (1652?). Séminaire diocésain (1748 à la fin du XVIII siècle).

Refuge des Trappistes de 1804 à 1806.

Séminaire jusqu'en 1818.

Refuge des Trappistes de Bellevaux (France) de 1831 à 1834.

Couvent de dominicains de 1875 à 1879 .

Institut de sourds-muets jusqu'en 1929.

Monastère de Bernardines (voir notice 39).

41. LA RIEDERA.

Trappistines.

Canton de Fribourg (Freiburg), d. Sarine, cm. Essert et Montévraz.

1/50.000', 252, 579/116; 1/100.000', 36; Mi., 23/5; Exc. J-7 $46^{\prime \prime} 43^{\prime} 58^{\prime \prime} \mathrm{N}-7^{\circ} 10^{\prime} 05^{\prime \prime} \mathrm{E}$.

Dioc. de Lausanne.

Vocable: N.-D. de la Sainte-Trinité

$8 \mathrm{~km}$ au sud de Fribourg; $9 \mathrm{~km}$ au nord de la Valsainte; $3 \mathrm{~km}$ à l'est de Treyvaux. Un peu à droite de la route n." 77 en direction de Fribourg. Indiqué sur Mi. par le signe de «chapelle». 
Les deux emplacements: Grande et Petite Riedera sont indiqués sur la feuille 1205 (Rossens) de la Carte Nationale Suisse au 1/25.(0)(0) sous le nom unique de «La Riedera».

Établissement des Trappistines venues de Paderborn. Elles s'établirent d'abord à Villarvolard (18()2), puis à la Grande Riedera en 1804, enfin à la Petite Riedera, le 18 novembre 1805 .

Supprimé en 1816. Les religieuses divisées en deux groupes rentrèrent en France. L'un de ces groupes fonda Les Gardes (Maine-et-Loire), l'autre Maubec (Drôme), après de brefs séjours dans des établissements provisoires.

Bibl:: A. Dellion, Dictionnaire des paroisses du Canton de Fribourg, Bd. 9, s. 195 (Fribourg, 1897): "Dom Augustin ramena en Suisse ses religieux et les religieuses. La princesse de Bourbon-Condé avait quitté les Trappistines pour rejoindre quelques membres de sa famille. Il rentrait à la Valsainte dans les premiers jours de mai 1803 , avec 87 religieux. Il établit les soeurs Trappistines à Villarvolard, d'abord; et ensuite à la Riedera».

\section{SAINT-PIERRE-DE-ClaGeS.}

Trappistes.

Canton du Valais, d. Conthey, $\mathrm{cm}$. Chamoson.

1/50.000, 272, 584/116; 1/100.000, 41; Mi., 23/15; Exc., N-8.

46"11'32" N - 7"14'15" E.

Dioc. de Sion (Sittich).

Route 9. Sur la rive droite du Rhône, entre Riddes et Ardon.

Prieuré bénédictin fondé en 1153 , dépendant de l'abbaye d'Ainay, à Lyon. Rattaché en 1580 à la mense épiscopale de Sion.

Établissement de Trappistes fondé en 1793 par le Père Gérard Bollangié, sous-prieur de la Trappe. Supprimé en 1795. Indépendant de la Valsainte. Bibl.: "Cistercienser-Chronik» (1929), p. 147.

\section{SEMBRANCHER.}

Trappistes et Trappistines.

Canton du Valais, d. Entremont, $\mathrm{cm}$. Sembranchez. Le monastère se trouvait sur le territoire de la commune voisine de Vollèges.

1/50.000; 282, 576/103; 1/100.0(0)", 46; Mi., 26/2; Exc., 0-7. $46^{\prime \prime}\left(04^{\prime} 50^{\prime \prime} \mathrm{N}-7^{\prime \prime}\left(07^{\prime} 52^{\prime \prime} \mathrm{E}\right.\right.$.

Dioc. de Sion (Sittich).

Ancien nom: SAINT-BRANCHIER (c'est sous ce vocable que ce monastère est désigné dans les histoires de la Trappe au XIX' siècle). Dérive de St Pancrace, devenu St Brancarius on Brancas au XII' siècle.

Route 114. Sur la rive droite de la Drance. À $1,6 \mathrm{~km}$ de la localité de Sembrancher, à l'ouest. Au passage à niveau, au lieu dit «Les Trappistes». 18 
$\mathrm{km}$ sud-sud-est/sud-est de Martigny-ville; 4() $\mathrm{km}$ sud-outest de Serre. Refuge de Trappistes et de Trappistines de 1796 a 1798. Il ne reste plus rien des deux maisons à part le monument érigé par l'Ordre des (isterciens de la Stricte Observance en 19()$S$ qui porte le texte suivant:

A LA MEMOIRE DF DOM AUGLSTIN DF: LISTRANGIS. ABBE DF LA TRAPPE DE I.A VALSAINTE FONDATEL DR DS DELX MONASTERES DE I.A SAINTE-VOIONTE-DE-DIFL SUR LISS RLINIS DISQUUILS A ETE ERIGE CE MONUMENT ET DES PIEUIX FILS DE SAINT BERNARD QUI CHASSES DE FRANCI PAR IA TOLIRMENTE RFVOLUlTIONNAIRE TROUVERINT INN ASILE IN CE LIEU.

$$
\text { 1796-1798 }
$$

BEATI QUI PERSECUTIONEM PATIUNTIIR PROPTER IIISTITIAM MCMV

\section{VAL.SAINTE.}

\section{Trappistes.}

Canton de Fribourg (Freiburg), d. Gruyere, cm. Cerniat.

1/50.(0)(0), 252, 581/167; 1/100.000\%, 36; Mi., 23/5; Exc., K-7. 46"39' 02 " $\mathrm{N}-7$ " (06' 30" E.

Dioc. de Lausanne. Genève-Fribourg.

$17 \mathrm{~km}$ au sud de Fribourg; $21 \mathrm{~km}$ sud-sud-est de Romont. Un peu à l'écart, sur la rive droite du Javro.

Refuge des Trappistes pendant la Révolution.

Ancienne chartreuse fondée en octobre 1295 (charte de fondation).

Supprimée en 1778.

Installation de Dom Augustin de Lestrange et de ses moines le $1^{\text {" juin }}$ 1791.

Suppression en février 1798.

Réouverture le 2 juillet 1802. Suppression en 1812 (suite du Décret de SaintCloud).

Réouverture en 1814. Suppression définitive en 1815. Les moines s'installent à la Grande-Trappe et à Aiguebelle.

Occupé par les chartreux depuis 1863.

Bibl. sommaire: Casimir GAILLARDIN, Les Trappistes ou l'Ordre de Cîteaux au XIX' siècle, Paris, 1844.

- Vie du vénérable Abbé D. Augustin de Lestrange, par un religieux de son Ordre,

2 édition, Aix, 1834.

- Odyssée monastique, D. Augustin de Lestrange, Grande-Trappe, 1898.

- Tobie de RAEMY, L'émigration française dans le Canton de Fribourg, Fribourg, 1945. 
45. VILLARVOLARD.

Trappistines.

Canton de Fribourg (Freiburg), d. Gruyere, cm. Villarvolard.

1/50.(0)(0), 252, 575/166;1/10().(0)(0), 36; Mi., 23/5; Exc. K-7.

$46^{\circ} 38^{\circ} 47^{\prime \prime} \mathrm{N}-76^{\circ}\left(16^{\circ} 3\right)^{\prime \prime} \mathrm{E}$.

Dioc. de Lausanne-Genève-Fribourg.

$18 \mathrm{~km}$ au sud-sud-ouest de Fribourg; $8 \mathrm{~km}$ au nord/nord-nord-est de Gruyères. Route 77, à l'est du lac de la Gruyère.

Établissement provisoire des religieuses venues de Paderborn, le 26 octobre 18() 2 .

Transféré à la Grande Riedera en 180.4.

46. WIDLISBACH.

Trappistes.

Vohable: N.-D. de la Miséricorde.

Canton de Solothurn (Soleure), d. Lebern, cm. Rüttenen.

1/50.00(0;, 223, 607/231;1/10().0(0); 31; Mi., 21/14; Exc. E-9.

$47^{\prime \prime} 14^{\prime}()()^{\prime \prime} \mathrm{N}-7^{\prime \prime 32}$ ' ()7" E.

Dioc. de Bâle.

2,5 km au nord-nord-est de Solothurn; $22 \mathrm{~km}$ au sud-est de Délémont.

Ne pas confondre avec Wiedlisbach, localité située à l'est.

Établissement de moines venus de la Trappe avec le Père Gérard Bollangié, sous-prieur. Ces moines ne voulurent pas se joindre à Dom de Lestrange installé à la Valsainte. Ils occupèrent une ferme nommée Glutzenbof et non Ponzenhof, comme il est indiqué dans la Cistercienser-Chronik (1929, pp. 11, 13, 46, 235). Ils séjournèrent ici de 1791 à 1795, année de la mort de Dom Gérard.

Bibl.: La "Cistercienser-Chronik», année 1929, a publié toute une série de lettres de Dom Gérard ainsi qu'une correspondance des abbés de Salem et de Wettingen concernant cette fondation.

Pour la localisation exacte de Widlisbach, lettre du Dr. A. Kocher, archiviste du Canton de Solothurn, en date du 27 avril 1962.

\section{RÉSUMÉ}

Ce travail étudie l'ordre cistercien en Suisse suivant le schéma suivant: A - Un résumé de l'histoire suisse. B - Le milieu géographique. C - L'implantation des abbayes de religieux et de religieuses. D-L'évolution de l'ordre entre 1131 et 1966. E-Les trappistes.

L'étude se termine sur un catalogue géographique détaillé et chronologique des abbayes cisterciennes en Suisse. 


\section{SUMMARY}

This work treats about the study of the Cistercian order in Switzerland, following this outline:

a. a synthesis of the history of Switzerland. b. the geographic surroundings. c. the implantation of abbeys with nuns and monks. d. the evolution of the Order between 1131 and 1966. e. the Trappists.

The study ends with a detailed geographical and chronological catalogue of the cistercian abbeys in Switzerland. 


\section{1._Filiation des Abbayes Cisterciennes en Suisse}

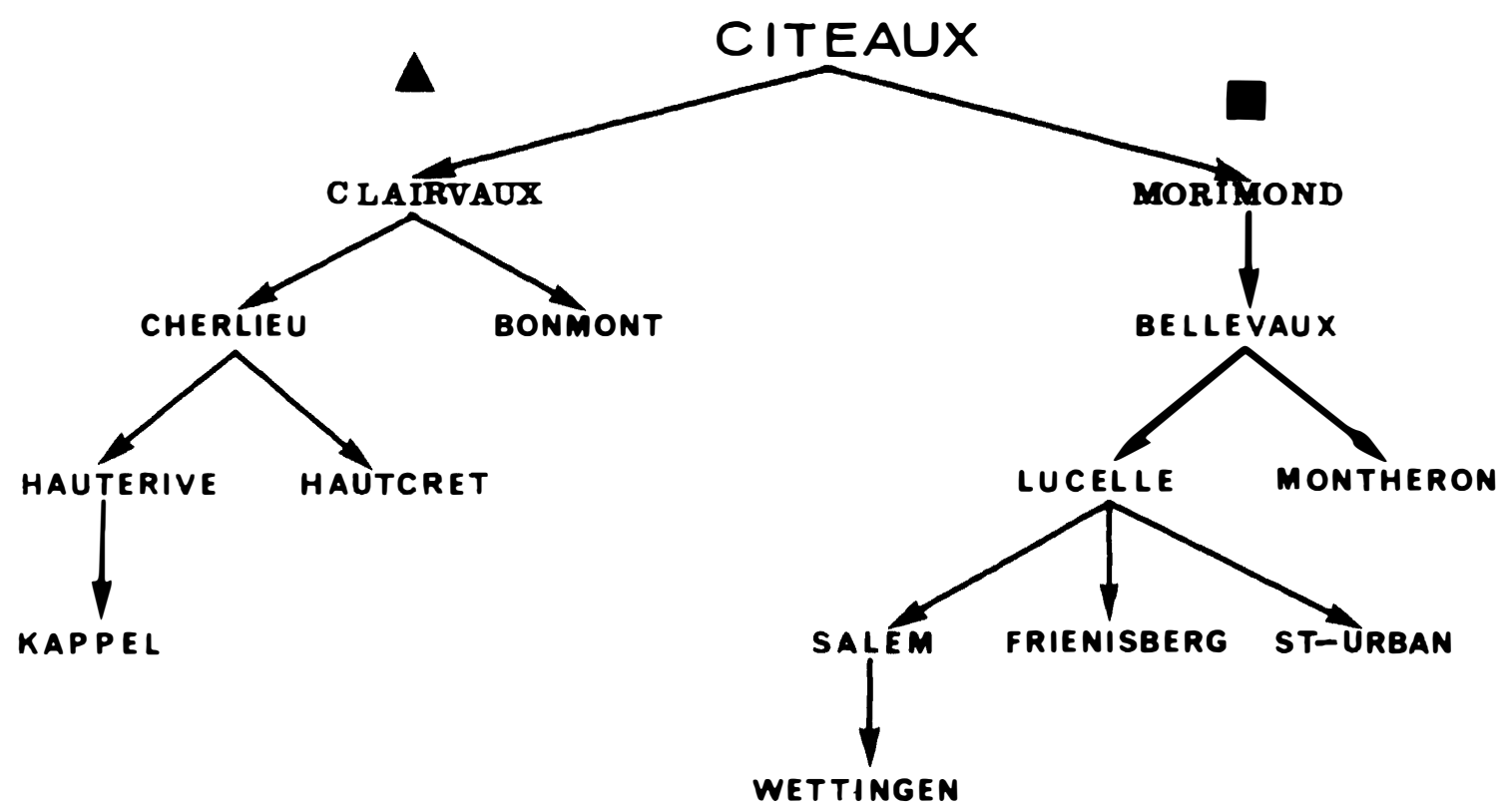




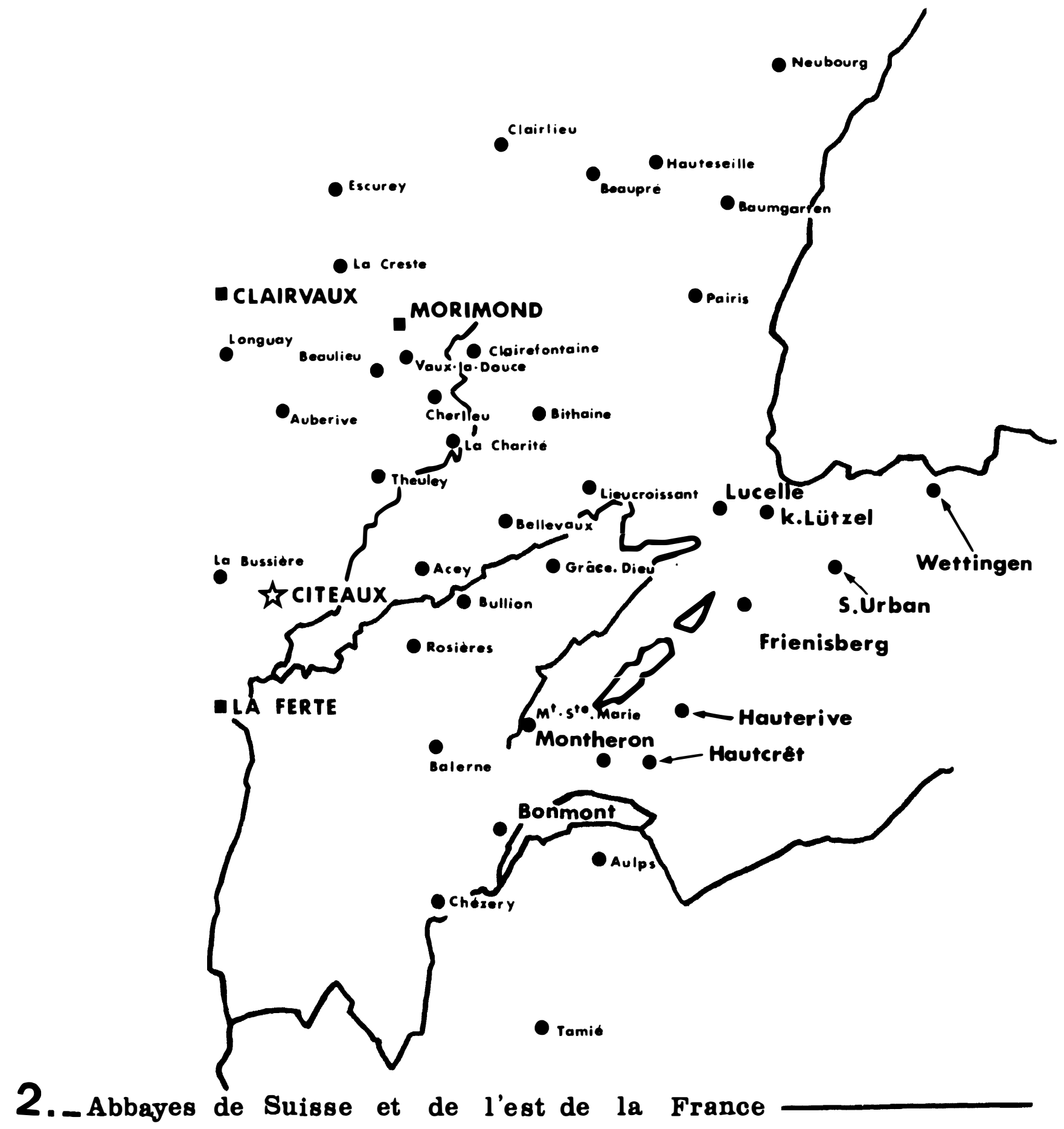




\section{3._Le rayonnement de la Valsainte}

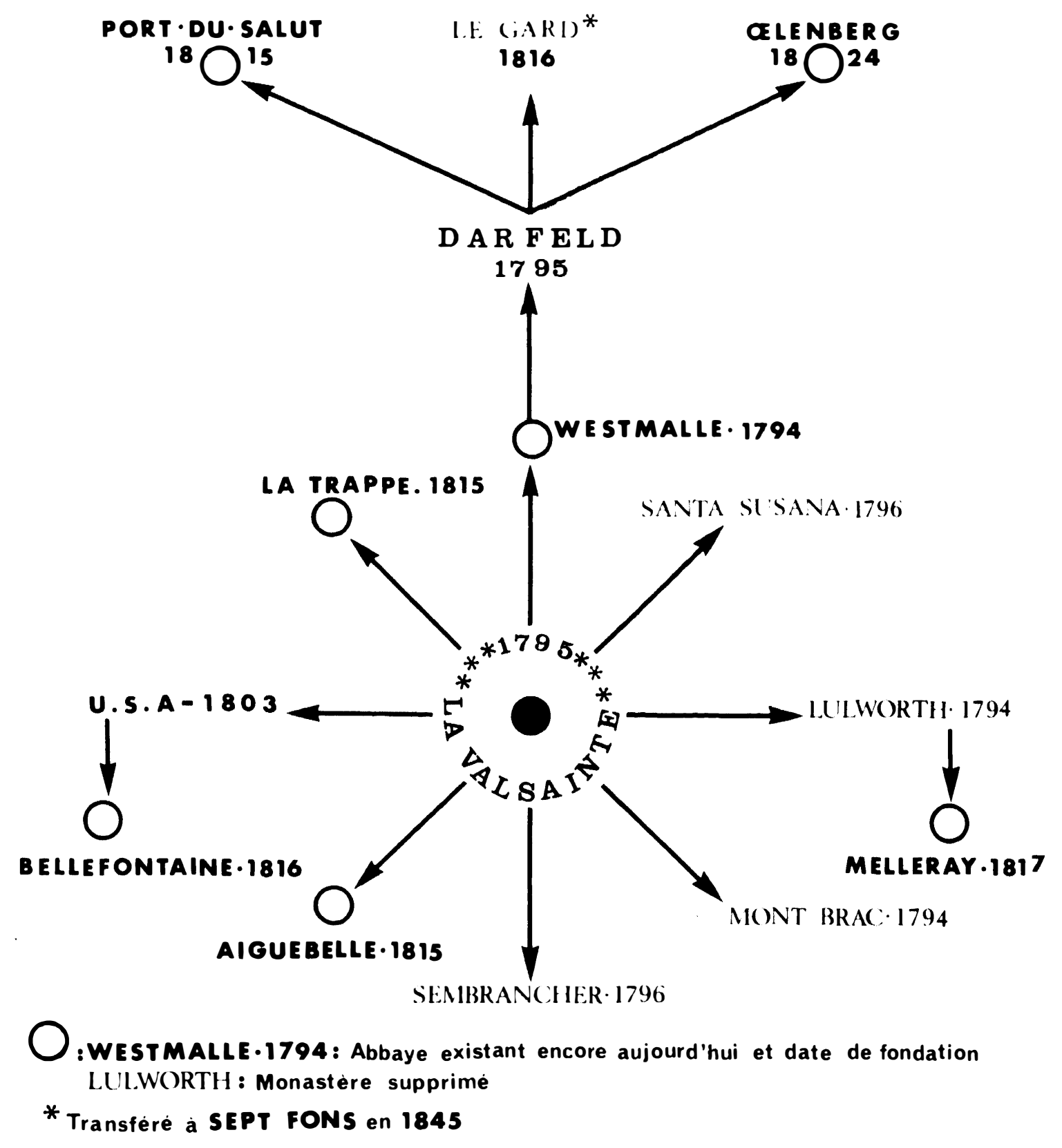




\section{4._Filiation de la Valsainte}

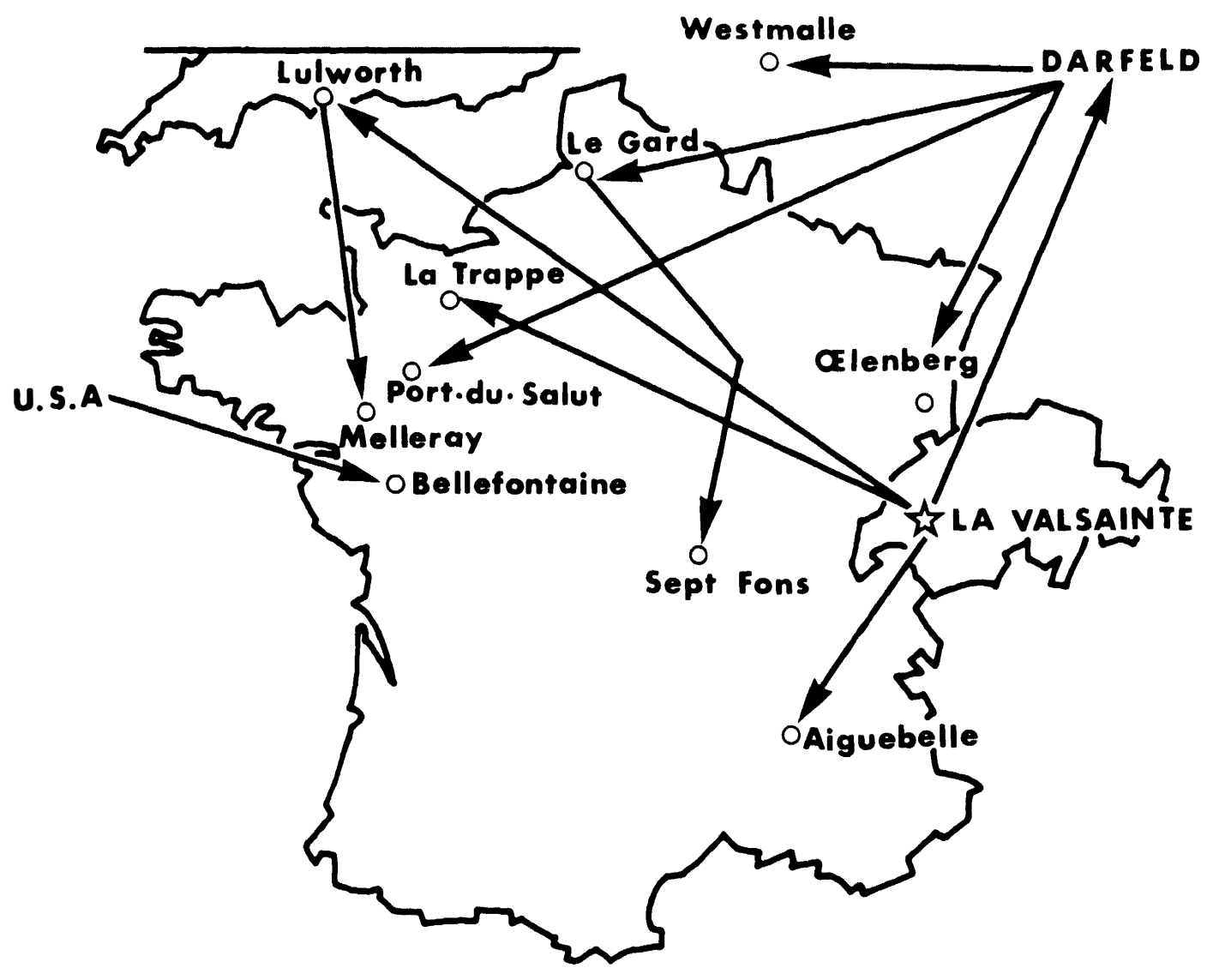

